\title{
Thermal-electrochemical parameters of a high energy lithium- ion cylindrical battery
}

\author{
Kieran O'Regan,,$^{\text {a,c, }}{ }^{*}$ Ferran Brosa Planella, ${ }^{\text {b,c }}$ W. Dhammika Widanage, ${ }^{\text {b,c }}$ and \\ Emma Kendrick. ${ }^{a, c, *}$ \\ aSchool of Metallurgy and Materials, University of Birmingham, Edgbaston, Birmingham, \\ BT15 2TT, UK \\ bWMG, University of Warwick, Gibbet Hill Road, Coventry, CV4 7AL, UK \\ 'The Faraday Institution, Quad One, Becquerel Avenue, Harwell Campus, Didcot, OX11 ORA, UK \\ *Corresponding author e.kendrick@bham.ac.uk, kieran@aboutenergy.co.uk.
}

\begin{abstract}
To accurately predict the lifetime of commercial cells, multi-physics models can be used, however the accuracy of the model is heavily reliant upon the quality of the input thermodynamics and kinetic parameters. The thermal properties and the variability of the transport and thermodynamic properties with temperature and state-of-charge (SoC) in a high energy 21700 cylindrical cell were measured. The parameters are used in a DFN and OD thermal model, and the model was tested against experimental data from the commercial cell. The results demonstrate an improved model fit by $27 \%$ when including the parameter dependency upon SoC and temperature, compared to without. The maximum power is limited by the negative electrode, which has lower diffusion coefficients and current exchange density over the full SOC window compared to the positive electrode, particularly at $50 \%$ and $80 \%$ SoC ( $x=0.45$ and 0.85$)$, reflected in high activation energies of up to $60 \mathrm{kJK}^{-1}$ and low diffusion coefficients of $5 \times 10^{-13} \mathrm{~cm}^{-2} \mathrm{~s}^{-1}$ at $25^{\circ} \mathrm{C}$. At $45{ }^{\circ} \mathrm{C}$, the reaction rate increases to greater than that of the positive, diffusion also increases, $2 \times 10^{-12} \mathrm{~cm}^{-2} \mathrm{~s}^{-1}$, but is still limiting. This work provides for the first time an electrochemical and thermal experimental dataset for a high energy cell, and provides insights into the rate limitations and prediction errors.
\end{abstract}

\subsection{Introduction}

Lithium-ion batteries are becoming a preferred technology for energy storage, particularly within the automotive industry due to a transition towards electric vehicles. ${ }^{1,2}$ Significant improvements in battery technology have been made, including reducing cost and increasing energy density. ${ }^{3}$ However, improving battery performance has an impact upon safety considerations due to increased heat generation inside the cell, which in turn increases the probability of thermal runaway. ${ }^{4,5}$ Therefore, the thermal characteristics of a cell are an important consideration during cell and pack design. ${ }^{6}$ Models can aid this design process by simulating the heat generation and electrochemical behaviour of a battery. ${ }^{7}$ Increasingly, physics-based models are being used for predictive purposes, providing insights into the internal states of a battery and more accurate predictions compared to equivalent circuit models. ${ }^{8}$ Through the porous electrode theory introduced in the work of Newman and Tiedemann, physics-based electrochemical models became popularised for predicting the internal states of a battery. ${ }^{9,10}$ These predictions can be further improved by coupling to a thermal model to capture the thermal-dependency. ${ }^{11,12}$ 
Higher energy density materials have been developed to meet the automotive specifications for lower cost vehicles, these include nickel-rich layered oxides and silicon-doped graphite electrodes. ${ }^{13,14}$ The development of new materials and cell types means that these systems need to be parameterised to enable accurate model predictions for these applications. This is because electrodes vary in composition and microstructure, factors that have significant influence on the resulting electrochemical and thermal properties. ${ }^{15}$ Commonly used parameter sets for commercial cells are not for high energy systems and do not include the information required to extend to a 3D thermal model. ${ }^{16-18}$ Recent parameterisations of commercial cells only considered batteries with electrodes less than $55 \mu \mathrm{m} .{ }^{17,19}$

Previous work has compared differences in energy vs power cells and their physical and electrochemical properties, these differences identified a need to parameterise high energy cells as literature has focussed on high power. ${ }^{20,21}$ Additionally, research that has parameterised thermal-electrochemical models has not involved measuring the specific heat capacities and thermal conductivities of the individual materials needed to describe thermal performance beyond OD (Table 1). ${ }^{18,22}$ The requirements of the different thermal model definitions are as follows (the electrochemical parameters also need to be defined):

- OD Thermal: Activation energy, entropic term, and lumped (volumetric) heat capacity.

- 1D Thermal: Thermal conductivity, heat capacities, and 1D cell geometry.

- 2D Thermal: 2D cell geometry.

- 3D Thermal: 3D cell geometry, tab locations, and inner structure.

In this paper we parameterise the LG M50, a cell that with a very high energy density $267 \mathrm{Wh} \mathrm{kg}^{-1}$, attributed to high electrode coat weight and its composition of $\mathrm{Li}\left[\mathrm{Ni}_{1-\mathrm{x}-\mathrm{y}} \mathrm{Mn}_{\mathrm{x}} \mathrm{CO}_{\mathrm{y}}\right] \mathrm{O}_{2}$ (NMC) and $\mathrm{SiO}_{\mathrm{y}}$ materials. To our knowledge, this is to date the highest energy cell reported in literature, for which parameterisation has been performed, and the only cell to have the thermal characteristics for the electrodes and cell $\left(267 \mathrm{Wh} \mathrm{kg}^{-1}\right)$. The parameterisation provides the modelling community with the data to predict thermal inhomogeneities within the cell by detailing the cell anatomy and the thermal transport properties required to extend to 3D. Including the information allows better predictions about battery performance to be made, therefore allowing more efficient thermal management systems to be designed. 
Table 1. A summary of physics-based model parameterisations of commercial cells in literature.

\begin{tabular}{|c|c|c|c|c|c|c|c|c|}
\hline & \multicolumn{2}{|c|}{ Properties } & \multirow{2}{*}{ Chemistry } & \multirow{2}{*}{$\begin{array}{c}\text { Electrochemical } \\
\text { DFN }\end{array}$} & \multicolumn{4}{|c|}{ Thermal } \\
\hline Paper & Cell Type & Wh/kg & & & OD & 1D & $2 \mathrm{D}$ & $3 D$ \\
\hline This work 2021 & $\begin{array}{c}5 \text { Ah LG } \\
\text { cylindrical } 21700\end{array}$ & 267 & $\begin{array}{c}\text { NMC811 } \\
\text { graphite }-\mathrm{SiO}_{\mathrm{y}}\end{array}$ & $\nabla$ & $\nabla$ & $\nabla$ & $\nabla$ & $\nabla$ \\
\hline Chen $2020^{23}$ & $\begin{array}{c}5 \text { Ah LG } \\
\text { cylindrical } 21700\end{array}$ & 267 & $\begin{array}{c}\text { NMC811 } \\
\text { graphite }-\mathrm{SiO}_{y}\end{array}$ & $\nabla$ & & & & \\
\hline Ecker $2015^{16}$ & $\begin{array}{c}7.5 \text { Ah Kokam } \\
\text { pouch }\end{array}$ & 173 & $\begin{array}{c}\text { NMC111 } \\
\text { Gr }\end{array}$ & $\nabla$ & & & & \\
\hline $\begin{array}{c}\text { Schmalstieg } \\
2018^{17}\end{array}$ & 28 Ah prismatic & - & $\begin{array}{l}\text { NMC111 } \\
\text { graphite }\end{array}$ & $\nabla$ & $\nabla$ & & & \\
\hline Liebig $2019^{18}$ & 40 Ah prismatic & - & $\begin{array}{l}\text { NMC111 } \\
\text { graphite }\end{array}$ & $\nabla$ & $\nabla$ & & & \\
\hline Sturm $2019^{22}$ & $\begin{array}{c}3.35 \text { Ah LG } \\
\text { cylindrical } 18650\end{array}$ & 211 & $\begin{array}{c}\text { NMC811 } \\
\text { graphite }-\mathrm{SiO}_{\mathrm{y}}\end{array}$ & $\nabla$ & $\nabla$ & & & \\
\hline Zulke $2021^{24}$ & $\begin{array}{c}\text { 4.8 Ah cylindrical } \\
21700\end{array}$ & 256 & $\begin{array}{c}\text { NCA } \\
\text { graphite }-\mathrm{SiO}_{\mathrm{y}}\end{array}$ & $\nabla$ & & & & \\
\hline
\end{tabular}

The M50 has become popular in the academic battery modelling community. The thermal parameters for this cell have not been outlined, meaning research has neglected the thermal behaviour or used properties not specific to the M50. ${ }^{23,25,26}$ Presently, the influence of temperature on the electrochemical behaviour has not been included or these properties required have been taken from a different cell. ${ }^{27}$ This work details the complete experimental design for a thermal-electrochemical parameterisation of a 21700 cylindrical cell to evaluate the geometric, electrochemical, and thermal properties of the electrodes, separator, and current collectors. In addition to providing the information necessary for a 3D thermal model, the lithium concentration and temperature parameter dependencies are documented to enable more accurate model predictions by accounting for the local variability in performance during cell operation. Models often neglect the effect of lithium concentration and temperature on cell properties, ${ }^{28,29}$ despite the parameters being significantly influenced by these variables. ${ }^{17}$ This includes the experimental methodology and the mathematical analysis to assess these parameter-dependencies, which can be applied to commonly used NMC and graphite materials.

The parameter requirements were based on the most commonly utilised electrochemical model developed by Doyle, Fuller, and Newman (DFN) outlined in Table S2. ${ }^{30}$ This paper focusses on presenting parameters relevant to capture 3D thermal behaviour, with equations outlined in Table S3. However, to validate the parameters against experimental data, a pseudo-two-dimensional (P2D) electrochemical coupled to a lumped (OD) thermal model was used. 


\subsection{Experimental}

\subsubsection{Teardown Procedure}

The battery investigated was a 5 Ah M50 21700 cylindrical cell manufactured by LG Chem. This cell utilises nickel-rich $\mathrm{NMC811}$ and $\mathrm{SiO}_{\mathrm{y}}$-graphite active materials. To extract the components the cell was discharged and disassembled in a glovebox. The teardown methodology has been described previously and detailed chemical and physical composition can be found in Table S1. ${ }^{23}$

During the teardown the gravimetric and volumetric contribution of each component was measured: the jellyroll was weighed immediately after disassembly, and again after the electrolyte had been evaporated to evaluate solvent content. The anatomy of the cell was detailed and the components were separated for individual analysis. To evaluate the mass of electrode coating the current collectors were delaminated. The positive electrode was soaked in $\mathrm{N}$-methyl-2-pyrrolidone (NMP) and sonicated at $70{ }^{\circ} \mathrm{C}$ to remove the coating. The negative electrode coating was removed using water. The measured weight of the bare current collectors was used to calculate the total black mass for each electrode. The electrode black mass was used to measure specific heat capacity. For further characterisation, a pristine cell was dismantled, and fresh electrodes extracted. For the electrochemical testing, one side of the coating had to be removed and to measure the thermal conductivity the double-sided electrode was left intact. Table 2 summarises details of the characterisation techniques and the parameters obtained from each experiment. The details of the techniques are described in Sections 1.3.3 and 1.3.4.

Table 2. Summary of parameterization techniques.

\begin{tabular}{|c|c|c|c|}
\hline & Technique & Parameter(s) & Details \\
\hline \multirow{2}{*}{ 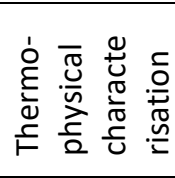 } & Differential scanning calorimetry & Specific heat capacity & $\begin{array}{l}25^{\circ} \mathrm{C} \text { and } 100^{\circ} \mathrm{C} \text { (continuous) } \\
\text { at SoC } 0 \%\end{array}$ \\
\hline & Laser flash analysis & Thermal diffusivity & $\begin{array}{l}-5{ }^{\circ} \mathrm{C} \text { to } 55^{\circ} \mathrm{C}\left(15^{\circ} \mathrm{C} \text { step }\right) \\
\text { at SoC } 0 \%\end{array}$ \\
\hline \multirow{4}{*}{ 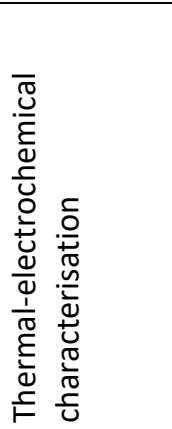 } & $\begin{array}{l}\text { Galvanostatic intermittent } \\
\text { titration technique }\end{array}$ & $\begin{array}{l}\text { Diffusivity and activation } \\
\text { energy }\end{array}$ & $\begin{array}{l}5^{\circ} \mathrm{C} \text { to } 45^{\circ} \mathrm{C}\left(10{ }^{\circ} \mathrm{C} \text { step }\right) \\
\text { at SoC } 0 \text { to } 100 \%\end{array}$ \\
\hline & Potentiostatic method & Entropic term & $\begin{array}{l}-5^{\circ} \mathrm{C} \text { to } 25^{\circ} \mathrm{C}\left(10{ }^{\circ} \mathrm{C} \text { step }\right) \\
\text { at SoC } 0 \text { to } 100 \%\end{array}$ \\
\hline & $\begin{array}{l}\text { Electrochemical impedance } \\
\text { spectroscopy }\end{array}$ & $\begin{array}{l}\text { Exchange current density } \\
\text { and activation energy }\end{array}$ & $\begin{array}{l}15{ }^{\circ} \mathrm{C} \text { to } 45^{\circ} \mathrm{C}\left(10{ }^{\circ} \mathrm{C} \text { step }\right) \\
\text { at SoC } 0 \text { to } 100 \%\end{array}$ \\
\hline & Four-point probe & $\begin{array}{l}\text { Electronic conductivity and } \\
\text { activation energy }\end{array}$ & $\begin{array}{l}15{ }^{\circ} \mathrm{C} \text { to } 35^{\circ} \mathrm{C}\left(5^{\circ} \mathrm{C} \text { step }\right) \\
\text { at SoC } 0 \%\end{array}$ \\
\hline
\end{tabular}




\subsubsection{Thermophysical Characterisation Differential Scanning Calorimetry (DSC)}

The specific heat capacities of the dried composite powders and the separator were evaluated by applying a continuous method on a DSC 1 from Mettler Toledo between $25^{\circ} \mathrm{C}$ and $100{ }^{\circ} \mathrm{C}$. The heating rate was set at $10 \mathrm{~K} \mathrm{~min}^{-1}$ with a sampling interval of $0.1 \mathrm{~s}$. Three repeats of the blank pans, sapphire reference, and the samples were measured. The sample weights were approximately $10 \mathrm{mg}$.

\section{Laser Flash Analysis (LFA)}

The through-plane thermal diffusivity was measured for the electrodes using laser flash analysis (LFA 467 HyperFlash, Netzsch). This measurement was carried out at temperatures of $-5{ }^{\circ} \mathrm{C}, 10{ }^{\circ} \mathrm{C}, 25^{\circ} \mathrm{C}, 40{ }^{\circ} \mathrm{C}$, and $55^{\circ} \mathrm{C}$ using a nitrogen purge gas. For this measurement samples of $20 \mathrm{~mm} \times 20 \mathrm{~mm}$ were used, each sample was measured five times at each temperature.

\subsubsection{Thermal-electrochemical Characterisation}

To deconvolute the behaviours of the negative and positive electrode a three-electrode configured PAT-Cell (EL-Cell) and a perfluoroalkoxy alkane Swagelok ${ }^{\text {TM }}$ half-cell (using lithium metal as the counter electrode) were utilised for the electrochemical testing. The three-electrode cell was comprised of an $18 \mathrm{~mm}$ negative and positive electrode, a $21.6 \mathrm{~mm}$ double layered separator comprised of $180 \mu \mathrm{m}$ polypropylene woven layer and a $38 \mu \mathrm{m}$ polyethylene membrane (EL-Cell), with $100 \mu$ l of electrolyte. The half-cell was comprised of a $11 \mathrm{~mm}$ working electrode, a $12 \mathrm{~mm}$ lithium counter electrode, $12.8 \mathrm{~mm}$ Celgard 2325 tri-layer separator (polypropylene/polyethylene/polypropylene) and $50 \mu \mathrm{l}$ of electrolyte. The electrolyte used was $1 \mathrm{~mol} \mathrm{dm}^{-3} \mathrm{LiPF}_{6}$ in ethylene carbonate: ethylmethylcarbonate $(3: 7, \mathrm{v}: \mathrm{v}$, Soulbrain). The electrochemical protocols were programmed on a VMP3 potentiostat (Bio-Logic). Electrochemical testing was preceded by two cycles of $\mathrm{C} / 20 \mathrm{CC}$ CV charge (CV cut-off was $\mathrm{C} / 50$ ) and $\mathrm{CC}$ discharge between $2.5 \mathrm{~V}$ and $4.2 \mathrm{~V}$. The C-rate was based upon the discharge capacity for the second cycle. For temperature control a programmable climatic chamber (Temperature Applied Sciences) with an accuracy of $\pm 1^{\circ} \mathrm{C}$ and a fan i.e. forced convection.

\section{Galvanostatic Intermittent Titration Technique (GITT)}

GITT was conducted at temperatures of $5^{\circ} \mathrm{C}, 15^{\circ} \mathrm{C}, 25^{\circ} \mathrm{C}, 35^{\circ} \mathrm{C}$, and $45^{\circ} \mathrm{C}$ in a three-electrode cell between $2.5 \mathrm{~V}$ and $4.2 \mathrm{~V}$. Transients were $\mathrm{C} / 10 \mathrm{CC}$ for 150 seconds and the relaxation period was limited to a duration of 2 hours or when the voltage decay with time was $\mathrm{dE} / \mathrm{dt}<0.1 \mathrm{mV} \mathrm{h}^{-1}$.

\section{Entropy Determination (Potentiostatic method)}

OCV measurements were carried out at temperatures of $25{ }^{\circ} \mathrm{C}, 15^{\circ} \mathrm{C}, 5{ }^{\circ} \mathrm{C},-5{ }^{\circ} \mathrm{C}$ at SoCs between $0 \%$ and $100 \%$ (10\% intervals) in a three-electrode cell. The cell was initially charged to $100 \%$ SoC with C/5 CC CV (C/50 cut-off), then was discharged for $1 \mathrm{~h}$ by a C/10 CC step at $25{ }^{\circ} \mathrm{C}$ i.e. to $90 \%$ SoC. The battery was subsequently allowed to relax for $15 \mathrm{~h}$ at the same 
temperature, after which the thermal cycle $\left(15^{\circ} \mathrm{C}, 2 \mathrm{~h} ; 5^{\circ} \mathrm{C}, 2 \mathrm{~h} ;-5^{\circ} \mathrm{C}, 2 \mathrm{~h}\right)$ was applied. This process was repeated until a final SoC of $0 \%$ was attained.

\section{Potentiostatic Electrochemical Impedance Spectroscopy (PEIS)}

PEIS measurements were conducted at SoCs between $10 \%$ and $100 \%$ for temperatures $15^{\circ} \mathrm{C}$, $25^{\circ} \mathrm{C}, 35^{\circ} \mathrm{C}$, and $45^{\circ} \mathrm{C}$ in a Swagelok half-cell. The sinusoidal current applied had an amplitude of $10 \mathrm{mV}$ and a $10 \mathrm{mHz}-100 \mathrm{kHz}$ frequency range. The data was analysed by fitting to an equivalent circuit model in Zview (Ametek).

\section{Four-point Probe}

The electronic conductivity of the positive electrode was evaluated at temperatures $15{ }^{\circ} \mathrm{C}$, $20{ }^{\circ} \mathrm{C}, 25^{\circ} \mathrm{C}, 30{ }^{\circ} \mathrm{C}$, and $35{ }^{\circ} \mathrm{C}$ using a four-point probe (Ossila Instruments). The positive electrode coating was delaminated using liquid gallium to dissolve the aluminium current collector and obtain the electrode coating undamaged. Small quantities of $1 \mathrm{~mol} \mathrm{dm}$ hydrochloric acid and deionised water were used to remove the gallium alloy. This methodology has been described in detail previously. ${ }^{31}$ To measure the electronic conductivity of the positive electrode a target current of $100 \mu \mathrm{A}$ was used, the voltage was stepped by $0.1 \mathrm{~V}$ until the target current had been reached.

\section{Model Validation}

The thermal-electrochemical model was validated for discharge rate capability tests at various temperatures, the temperature during these experiments was monitored to validate the heat generation component of the model. The heat generation was measured using an external thermocouple on the cylindrical cell. Before the experiment there is a two hour rest period to record the initial state. Then the cell was charged at $0.3 \mathrm{C}$ with a $\mathrm{C} / 100$ current cutoff for the CV step, and discharged at $\mathrm{C} / 10, \mathrm{C} / 2,1 \mathrm{C}$, and $2 \mathrm{C}$ using a Maccor battery tester. The voltage window used was $2.5 \mathrm{~V}-4.2 \mathrm{~V}$. Between each charge and discharge there was a two hour rest period. The testing protocol was carried out at $0{ }^{\circ} \mathrm{C}, 10^{\circ} \mathrm{C}$, and $25^{\circ} \mathrm{C}$ with the chamber temperature being measured throughout the experiment.

\subsubsection{Simulations}

Simulations were conducted in the Python Battery Mathematical Modelling (PyBaMM) software package (using v0.4.0). ${ }^{32}$ The equations for the thermal-electrochemical model are summarised in Table S2 and Table S3. In order to solve the model a finite volume scheme was used, with 30 grid points for each electrode and the separator, and 150 grid points for each particle; resulting in a system of 9092 ODEs and 150 algebraic equations. An exponential mesh was used to help with the convergence of the solver. In order to solve the system, a CasADI solver was used. ${ }^{33}$ Each simulation of discharge plus relaxation takes 10 to 20 minutes using an Intel Core i7-7660U $(2.50 \mathrm{GHz})$ processor and 16 GB RAM. This is because the nonlinear diffusion takes the solver many iterations to converge. The computational time could be reduced by using more sophisticated numerical methods, but this is out of the scope of this work. It should be noted that reduced models such as the Thermal Single Particle Model with electrolyte $(\text { TSPMe })^{25}$ yield very similar results with a significant reduction of the computational time. 


\subsection{Results and Discussion}

\subsubsection{Cell Structure}

The cell structure describes the geometry and the anatomy, this information is needed to resolve a $3 \mathrm{D}$ thermal model. ${ }^{27}$ The structure can be used to build a complex model to predict inhomogeneities due to detail relating to the internal cell layered-structure, including tab location, winding structure, and gravimetric contributions.

The cell is comprised of a of high nickel $\mathrm{Li}\left[\mathrm{Ni}_{1-\mathrm{x}-\mathrm{y}} \mathrm{Mn}_{x} \mathrm{Co}_{y}\right] \mathrm{O}_{2}$ positive electrode material and a $\mathrm{SiO}_{y}$-graphite negative electrode, with a ceramic-coated polyolefin separator. ${ }^{23}$ This information and the specifications provided by the manufacturer are summarised in Table S1. The dimensions of the cell including and tab locations are illustrated in Figure 1, with the tabs are located at opposite ends; from the top view, the positive tab is positioned $90^{\circ}$ clockwise from the negative tab. The positive tab is $7.0 \mathrm{~cm}$ in length and is visible from both sides, whereas the negative tab is $5.0 \mathrm{~cm}$ in length and only visible from the side that has the electrode coating facing the inside of the jellyroll. Photographs of these tabs can be found in the Figure S2 with their dimensions are outlined in Table 3.

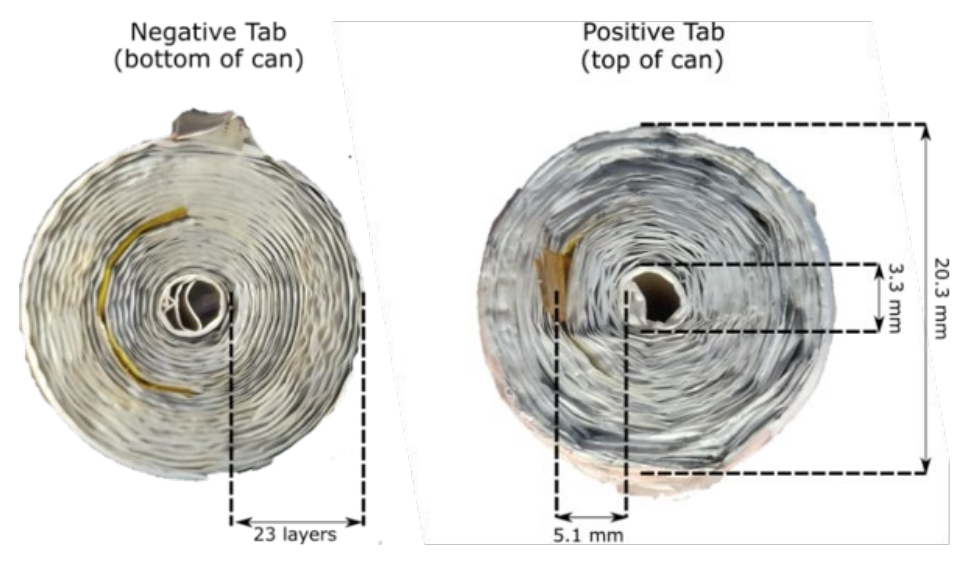

Figure 1. Tab locations (left) and a macro-view to illustrate tab positioning (right).

The cell jellyroll is electrically isolated from the cell casing by a thin plastic layer (thickness $20 \mu \mathrm{m}$ ) in the radial direction. In the axial direction, there is a thick plastic disc (thickness $0.22 \mathrm{~mm}$ ) at the bottom and a perforated fibrous membrane (thickness $0.2 \mathrm{~mm}$ ) at the top (Figure S1). These components significantly lower the axial thermal conductivity by forming a barrier for heat conduction through the current collectors to the casing. The jellyroll is comprised of an electrode stack of two separators, a double-side coated positive electrode, and a double-side coated negative electrode. The copper current collector was not completely coated (Figure S1). The jellyroll consisted of ca. 23 windings of the electrode stack, with the schematic of a single stack illustrated in Figure 2. 


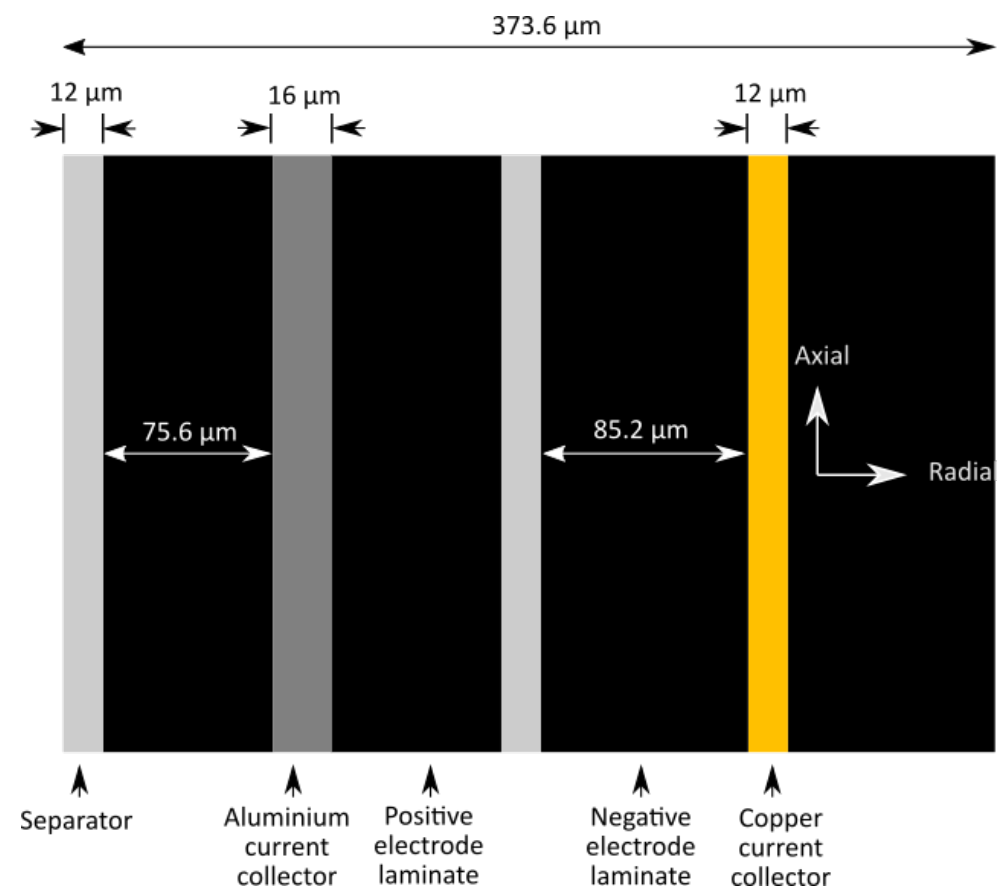

Figure 2. Schematic of an individual electrode layer.

The gravimetric and volumetric contributions of the components are summarised in Table 4. Immediately after disassembly, all the components of the cell were measured to account for solvent lost via evaporation. The jellyroll mass included any electrolyte still present and that lost during disassembly. The remaining solvent was evaporated to obtain a total electrolyte mass of $3.33 \mathrm{~g}$. For the electrolyte assumed in this investigation, $1 \mathrm{~mol} \mathrm{dm}^{-3} \mathrm{LiPF}_{6}$ in 3:7 EC:EMC (v:v), this corresponded to a salt content of $0.47 \mathrm{~g}$, and a total electrolyte mass of $3.80 \mathrm{~g}$. It was assumed this salt content was equally distributed within the separator and electrode coatings, these contributions were subtracted from the components. The mass of the separator, positive electrode, and negative electrode windings were $1.96 \mathrm{~g}, 28.96 \mathrm{~g}$, and $22.36 \mathrm{~g}$. After delaminating the coatings, the black mass of the individual components was evaluated. The volumetric contribution of each component could then be calculated, these are outlined in Table 4, with the densities of copper, aluminium, the stainless steel cell casing, and the electrolyte taken from literature. ${ }^{34,35}$ 
Table 3. Properties and anatomy of the cell. *With electrolyte **Surface area of jellyroll.

\begin{tabular}{|c|c|c|}
\hline Property & Unit & Value \\
\hline Volumetric energy density & Wh L L & 752 \\
\hline Specific energy density & Wh kg ${ }^{-1}$ & 267 \\
\hline Jelly roll width/height & $\mathrm{m}$ & $2.03 \cdot 10^{-2} / 6.58 \cdot 10^{-2}$ \\
\hline Jelly roll volume & $\mathrm{m}^{3}$ & $2.13 \cdot 10^{-5}$ \\
\hline Jelly roll surface area** & $\mathrm{m}^{2}$ & $4.84 \cdot 10^{-3}$ \\
\hline Cell width / length & $\mathrm{m}$ & $2.1 \cdot 10^{-2} / 71 \cdot 10^{-2}$ \\
\hline Casing thickness & $\mathrm{m}$ & $3.4 \cdot 10^{-4}$ \\
\hline Cell volume & $\mathrm{m}^{3}$ & $2.43 \cdot 10^{-5}$ \\
\hline Negative tab width / length / thickness & $\mathrm{m}$ & $4.00 \cdot 10^{-3} / 5 \cdot 10^{-2} / 1 \cdot 10^{-4}$ \\
\hline Negative tab position & - & Figure S1 \\
\hline Positive tab width / length / thickness & $\mathrm{m}$ & $3.5 \cdot 10^{-3} / 7 \cdot 10^{-2} / 1 \cdot 10^{-4}$ \\
\hline Positive tab position & - & Figure S1 \\
\hline Mass of cell & $\mathrm{kg}$ & $6.83 \cdot 10^{-2}$ \\
\hline Mass of jellyroll* & $\mathrm{kg}$ & $5.71 \cdot 10^{-2}$ \\
\hline
\end{tabular}

Table 4. Gravimetric and volumetric contributions of components within the cell. *Electrolyte is excluded from volume calculation as it is soaked into the electrodes and separator.

\begin{tabular}{|l|c|c|}
\hline Component & Weight /g & Volume $/ \mathrm{cm}^{3}$ \\
\hline Negative electrode coating & $16.51(24.2 \%)$ & $9.49(41.2 \%)$ \\
\hline Copper foil & $5.85(8.6 \%)$ & $0.66(2.9 \%)$ \\
\hline Positive electrode coating & $26.09(38.3 \%)$ & $7.98(35.1 \%)$ \\
\hline Aluminium foil & $2.87(4.2 \%)$ & $1.06(4.7 \%)$ \\
\hline Separator & $1.96(2.9 \%)$ & $2.07(9.1 \%)$ \\
\hline Electrolyte (incl. LiPF 6$)$ & $3.80(5.6 \%)$ & $3.12 *$ \\
\hline Casing & $10.64(15.6 \%)$ & $1.35(5.9 \%)$ \\
\hline Other & $0.39(0.6 \%)$ & $0.10(0.4 \%)$ \\
\hline Jellyroll & 57.08 & 21.3 \\
\hline Cell & 67.25 & 24.2 \\
\hline
\end{tabular}

\subsubsection{Thermophysical Characterisation}

This section outlines the properties needed to accurately predict thermal transport and local temperature inhomogeneities in a cell. Information including the specific heat capacities and thermal conductivity of each material is often not outlined or measured in cell parameterisations. ${ }^{16,17}$ This information can be combined with details of cell anatomy to construct an accurate 3D thermal model. Table 7 describes the thicknesses, densities, specific heat capacities, and thermal conductivities for all the individual cell components. This allows model to capture this detail rather than using macro-properties for thermal transport.

The specific heat capacity of the active materials was measured from the composite powders, whereas the thermal conductivity could not be measured directly so thermal diffusivity is measured first to calculate it. The thermal properties of the components should be considered with the presence of electrolyte as the commercial cell is comprised this way and the electrolyte significantly effects thermal transport. ${ }^{19,36}$ However, due to the volatility of the electrolyte, ex situ measurements could not be carried out for the separator or electrode and in situ measurements do not allow the deconvolution of the thermal properties of individual components-this is needed to enable physics-based models to predict thermal inhomogeneities. Here we outline a method to calculate the thermal properties of the wetted electrode using experimental data from the extracted electrodes. 
It is important to directly measure the thermal properties of the electrodes as microstructure significantly effects heat transport and generation within the battery. ${ }^{15,37}$ However, due to difficulty extracting any usable quantity of electrolyte, the thermal properties of a known electrolyte $1 \mathrm{~mol} \mathrm{dm}^{-3}$ LiPF $_{6}$ in 1:1:1 EC:EMC:DMC (v:v) was used (this is dissimilar from the electrolyte used in the electrochemical tests and model which is $1 \mathrm{~mol} \mathrm{dm}^{-3} \mathrm{LiPF}_{6}$ in 3:7 EC:EMC (v:v)). ${ }^{35}$ The heat capacity and thermal conductivity of this electrolyte were used in the following section as LiPF $_{6}$ in carbonate electrolytes are assumed to have similar properties and the model is not significantly sensitive to electrolyte parameters, the information is summarised Table 7. ${ }^{24}$

The following measurements were carried out on materials extracted from a cell fully discharged to $2.5 \mathrm{~V}$ i.e. $0 \% \mathrm{SoC}$. The effect of lithiation on the thermophysical properties of these materials was not considered here due to the difficulty in maintaining air stability at higher states of charge. It should be noted that the state of lithiation does significantly influence heat transport properties as described in a previous work, it was shown that the thermal diffusivity only changed by $15 \%$ for $\mathrm{LiNi}_{1-\mathrm{x}-\mathrm{y}} \mathrm{Mn}_{\mathrm{x}} \mathrm{Co}_{\mathrm{y}} \mathrm{O}_{2}$ across the whole lithium stoichiometry range. ${ }^{38}$ In practice, the change would be less significant as the materials are never fully lithiated/delithiated.

\section{Specific Heat Capacity}

The specific heat capacity describes the heat energy required to raise a material by a unit of energy, this relates to how easily the temperature rises within a cell and helps the model to predict temperature gradients. Selection of materials with a high specific heat capacity means more energy is needed to raise the internal temperature of a cell reducing the presence of internal gradients. This property was measured for the delaminated electrode powders and the separator as it is not dependent on microstructure (Figure 3). The values for the black masses provide an aggregate heat capacity for the active material, binder, and carbon black. The reported specific capacities corroborate the values reported previously for a NMC/graphite battery. ${ }^{19}$
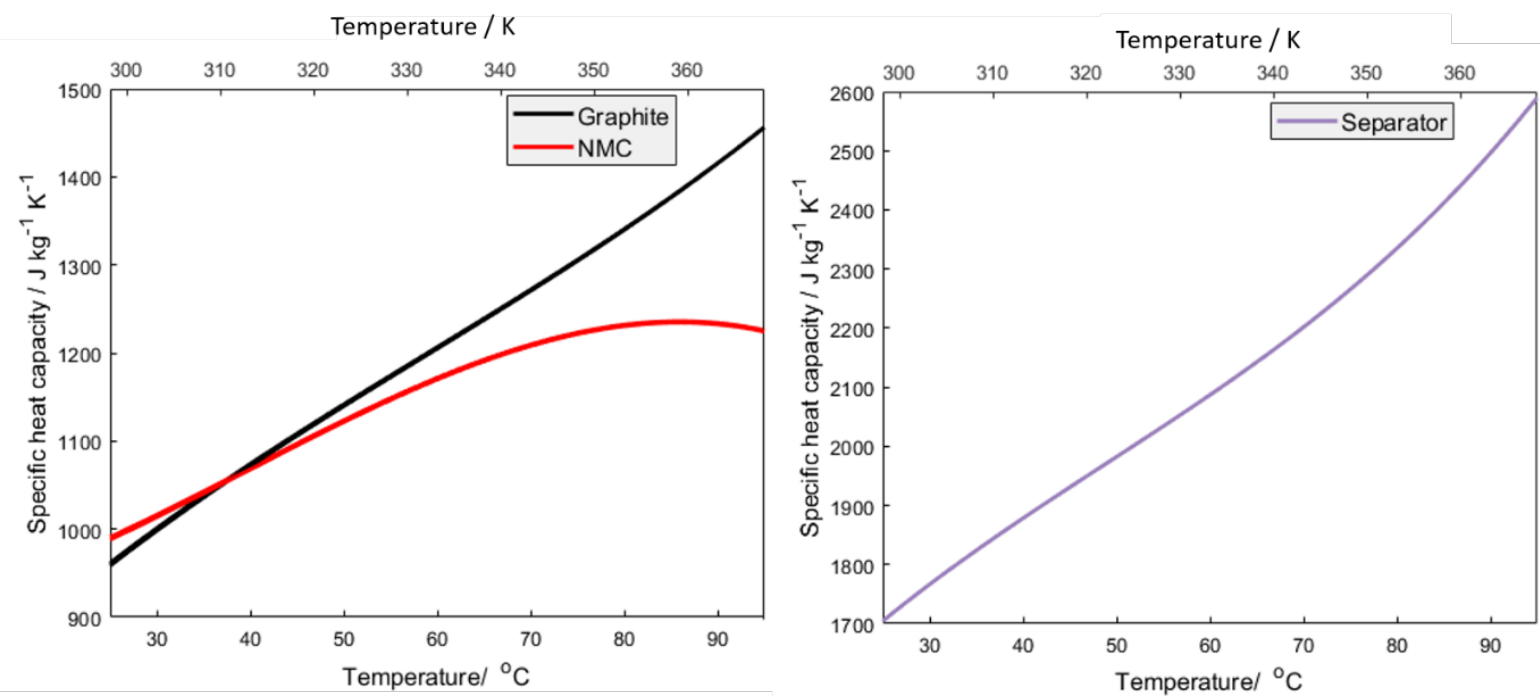
Figure 3. Specific heat capacities for the NMC composite powder (red), the graphite composite powder (black), and the separator (purple). The specific heat capacities for the NMC powder, graphite powder, and separator are represented by Equations [S1] to [S3]. To capture the change in specific heat capacity due to temperature in the model a function is needed to describe this relationship. The Debye theory of specific heat states that the specific heat of solids is proportional to $T^{3}$ if the temperature is below the Debye temperature, which is reported to be $141^{\circ} \mathrm{C}$ for graphite and between $136{ }^{\circ} \mathrm{C}-204{ }^{\circ} \mathrm{C}$ for the transition metals in NMC. ${ }^{39}$ We can therefore fit the specific heat capacity against temperature data using third order polynomial according to Debye theory, it is important to capture these phenomena using scientifically-robust descriptions rather than arbitrary functions. The fits for the electrode powders and separator are illustrated in Figure 3 with the comparison to raw data in Figure S3.

The current collectors also make a notable proportion of the cell mass (>7\%) so the variability of the specific heat capacities can also be captured to better predict local inhomogeneities in temperature. The heat capacities across the normal temperature operating range of a battery for aluminium and copper were taken from literature and fitted to third order polynomials to capture the parameter-dependency using Debye theory (where $T$ is in Kelvin and units are $\left.\mathrm{J} \mathrm{kg}^{-1} \mathrm{~K}^{-1}\right)$. These relationships are outlined in Equations [S4] and [S5]. ${ }^{34}$ The decreasing NMC specific heat capacity above $80^{\circ} \mathrm{C}$ could be due to decomposition of the binder within the sample, as there are no phase transitions within this range. ${ }^{40}$ However, this is beyond the normal operating range of a battery cell so this information would not be captured by the simulations.

The effect of the electrolyte is included by calculating the volumetric heat capacity for the wetted electrode from the volumetric heat capacities of each bulk material as shown in Equation [1]:

$$
\bar{\theta}=\rho_{s} \cdot C_{p, s} \cdot \varepsilon_{s}+\rho_{l} \cdot C_{p, l} \cdot \varepsilon_{l} .
$$

$\bar{\theta}$ is the averaged volumetric heat capacity; while $\rho, C_{p}$, and $\varepsilon$ are the density, gravimetric heat capacity and volume fraction for the electrode and electrolyte, respectively. The densities and the specific heat capacities of the electrolytes and the dry electrodes can be found in Table 7, and the electrolyte volume fraction in the positive and negative electrode is 0.335 and 0.25 respectively. Similarly, the averaged density $\bar{\rho}$ of the saturated electrodes can be calculated from the densities of the electrode solid and liquid components:

$$
\bar{\rho}=\rho_{s} \cdot \varepsilon_{s}+\rho_{l} \cdot \varepsilon_{l} \text {. }
$$

The volumetric heat capacity for the wetted positive electrode and wetted negative electrode are $3335500 \mathrm{~J} \mathrm{~m}^{-3} \mathrm{~K}^{-1}$ and $1743680 \mathrm{~J} \mathrm{~m}^{-3} \mathrm{~K}^{-1}$. Then the gravimetric heat capacity of the wetted electrodes is calculated by dividing the averaged volumetric heat capacity (calculated above) by the averaged density of the saturated electrodes $\left(3700 \mathrm{~kg} \mathrm{~m}^{-3}\right.$ and $2060 \mathrm{~kg} \mathrm{~m}^{-3}$ for positive and negative electrode). This provides a gravimetric heat capacity of $900 \mathrm{~J} \mathrm{~kg}^{-1} \mathrm{~K}^{-1}$ and $845 \mathrm{~J} \mathrm{~kg}^{-1} \mathrm{~K}^{-1}$ for the wetted positive electrode and negative electrode (without the current collectors) at $25^{\circ} \mathrm{C}$. As the specific heat capacity of the dry electrode bulk (powder) varies with temperature, this dependency can be included for the wetted electrode: 


$$
\overline{C_{p}}=\frac{\bar{\theta}}{\bar{\rho}}
$$

Here $\bar{\theta}$ and $\bar{\rho}$ are calculated from [1] and [2] respectively, the other values are summarised in Table 6.

Table 5. Values used to calculate the specific heat capacity of the wetted porous electrodes and separator.

\begin{tabular}{|c|c|c|c|}
\hline Parameter & NMC811 & Graphite-SiOy $_{y}$ & Separator \\
\hline Density of porous material $\left(\rho_{s}\right) / \mathrm{kg} \mathrm{m}^{-3}$ & 3270 & 1740 & 946 \\
\hline Heat capacity of bulk material $\left(C_{p, s}\right) / \mathrm{kg} \mathrm{m}^{-3}$ & Eq. S1 & Eq. S2 & Eq. S3 \\
\hline Density of electrolyte $\left(\rho_{l}\right) / \mathrm{kg} \mathrm{m}^{-3}$ & 1280 & 1280 & 1280 \\
\hline Heat capacity of electrolyte $\left(C_{p, l}\right) / \mathrm{J} \mathrm{K}^{-1} \mathrm{~kg}^{-3}$ & 229 & 229 & 229 \\
\hline Elecrolyte volume fraction $\left(\varepsilon_{l}\right)$ & 0.335 & 0.25 & 0.47 \\
\hline Density of wetted material $\left(\rho_{s+l}\right) / \mathrm{kg} \mathrm{m}^{-3}$ & 3700 & 2060 & 1620 \\
\hline
\end{tabular}

\section{Thermal Conductivity}

The thermal conductivity describes the ability of a material to conduct heat and heat transport within the cell. This is influenced significantly by the anisotropic structure of a cell and means that the thermal conductivities of the individual components can be evaluated to predict thermal gradients. For the electrode materials the thermal conductivity $\lambda$ was obtained from the following Equation [4] :41

$$
\lambda=\alpha \rho C_{p}
$$

Here $C_{p}$, is the specific heat capacity, $\rho$ is the density, and $\alpha$ is the thermal diffusivity. It was not possible to measure the thermal diffusivity of the separator as it is too thin to be characterised using laser flash analysis (LFA). The electrolyte volume fraction of traditionally used PP/PE/PP separator does significantly affect the thermal conductivity, therefore the thermal diffusivity is assumed to be similar across commercially used separator materials. ${ }^{42}$ The thermal conductivity of a wetted separator with similar properties is taken from literature, this is $0.3344 \mathrm{~W} \mathrm{~m}^{-1} \mathrm{~K}^{-1} .43$ The density and the volumetric specific heat capacity of the wetted separator can be evaluated using Eq. [1]. At $25^{\circ} \mathrm{C}, \rho, C_{p}$, and $\varepsilon_{l}$ are $946 \mathrm{~kg} \mathrm{~m}^{-3}$, $1700 \mathrm{~J} \mathrm{~kg}^{-1} \mathrm{~K}^{-1}$ and 0.47 for the dry separator. The volumetric heat capacity is $1745970 \mathrm{~J} \mathrm{~m}^{-3} \mathrm{~K}^{-1}$. This corresponds to a density and gravimetric specific heat capacity of $1620 \mathrm{~kg} \mathrm{~m}^{-3}$ and $1080 \mathrm{~J} \mathrm{~kg}^{-1} \mathrm{~K}^{-1}$ for the wetted separator. Therefore the heat capacity for the wetted separator is represented by Equation [1], where $C_{p, s}$ is defined by Equation [S3], and the other values are summarised in Table S5.

For the electrodes, this property cannot be determined from the powder as it is influenced by microstructure. ${ }^{15}$ Instead, the through-plane thermal diffusivity of the double-side coated electrode is measured. The through-plane thermal diffusivity and calculated specific heat capacities of the double-sided electrodes are illustrated in Table 6. The overall specific heat capacity of the electrodes were calculated using the heat capacities and mass fractions (Figure 3 ) of the black mass and current collectors. The area density of the positive electrode was 
attributed to $8.1 \%$ aluminium and $91.9 \%$ NMC coating, whereas the area density of the negative electrode was attributed to $26.6 \%$ copper and $73.4 \%$ graphite coating.

The thermal diffusivity decreases with temperature for both electrodes, although as the specific heat capacity relationship with temperature is inversely proportional, the thermal conductivity does not change significantly with temperature. The through-plane thermal conductivity of the graphite-SiOy electrode increases slightly, whereas the NMC electrode decreases slightly.

The thermal diffusivity and the specific heat capacity of the double-sided electrodes are used to calculate the overall thermal conductivity for the positive and negative electrode respectively. As the electrode is a layered material the conductivity of the electrode lamina can be deconvoluted. The conductivity in the in-plane direction is the harmonic average of the conductivities (weighted by their thickness). In this case, there were three layers, two layers of the electrode laminate and one layer of the current collector. Therefore, the thermal conductivity perpendicular to the electrode can be written as: ${ }^{4}$

$$
\lambda_{\text {total }}=\frac{L_{e 1}+L_{c c}+L_{e 2}}{\left(\frac{L_{e 1}}{\lambda_{e 1}}+\frac{L_{c c}}{\lambda_{c c}}+\frac{L_{e 2}}{\lambda_{e 2}}\right)}=\frac{2 L_{e}+L_{c c}}{\left(\frac{2 L_{e}}{\lambda_{e}}+\frac{L_{c c}}{\lambda_{c c}}\right)} .
$$

The thickness of the electrode $L_{e}$ and current collector $L_{c c}$, the conductivity of the current collector $\lambda_{c c}$ and the total conductivity $\lambda_{\text {total }}$ are known, therefore the conductivity of the electrode laminate $\lambda_{e}$ can be calculated. This corresponds to $0.807 \mathrm{~W} \mathrm{~m}^{-1} \mathrm{~K}^{-1}$ and $3.793 \mathrm{~W} \mathrm{~m}^{-1} \mathrm{~K}^{-1}$ at $25{ }^{\circ} \mathrm{C}$ for the NMC811 and graphite composite laminates respectively, values measured between $-5{ }^{\circ} \mathrm{C}$ and $55^{\circ} \mathrm{C}$ are reported in Table 6 . These thermal conductivities are in a similar range to reported values of 1.31 to $2.62 \mathrm{~W} \mathrm{~m}^{-1} \mathrm{~K}^{-1}$ and 0.68 to $2.62 \mathrm{~W} \mathrm{~m}^{-1} \mathrm{~K}^{-1}$ for NMC811 and graphite respectively. ${ }^{42}$

The thermal conductivity measurements were for the dry porous electrode, although the properties of the wetted electrode are required. The measurement included the contribution of the nitrogen purge gas and not the electrolyte, however $\mathrm{N}_{2}$ exhibits similar thermal conductivity $\left(0.025 \mathrm{~W} \mathrm{~m}^{-1} \mathrm{~K}^{-1}\right)$ to the electrolyte $\left(0.03 \mathrm{~W} \mathrm{~m}^{-1} \mathrm{~K}^{-1}\right)$ so the thermal conductivity of the wetted and dry electrode are assumed the same. The graphite and NMC thermal conductivities were fitted as interpolants in the model as low order polynomials did not provide good agreement.

The thermal conductivity for aluminium and copper current collectors were taken from literature as in batteries they appear in their pure elemental form and the thermal properties do not vary. The thermal conductivity of aluminium does not change appreciably within the operating range of the battery so the constant value of 237 in $\mathrm{W} \mathrm{m}^{-1} \mathrm{~K}^{-1}$ is used. However, the thermal conductivity for the copper decreases with temperature. The dependency of thermal conductivity on temperature is fitted to a third degree polynomial to capture this change in the model (where $x$ is in Kelvin and in $\lambda$ is in $\mathrm{W} \mathrm{m}^{-1} \mathrm{~K}^{-1}$ ), see Equation S6. ${ }^{34}$

These measurements allow prediction of thermal inhomogeneity within a cell, but combining these values do not provide an accurate value for the overall cell thermal conductivity. This is 
because of the cumulative error in measuring several materials separately and by not accounting for the thermal contact resistances between the layers in a cell. For accurate 3D thermal models and to predict the performance of larger battery systems the macro-thermal properties need to be measured. Cylindrical cells are a composite and not a pure material, therefore the conductivity of each cell type has to be measured to improve prediction of the cell temperature.

Table 6. Summary of the thermal diffusivity, specific heat capacity and thermal conductivity values for NMC811 and graphite electrodes as a function of temperature.

\begin{tabular}{|l|c|c|c|c|c|}
\hline & \multicolumn{5}{|c|}{ Thermal Diffusivity / $\alpha / \mathrm{mm}^{2} \mathrm{~s}^{-1}$} \\
\hline Temperature / K & 268.15 & 283.15 & 298.15 & 313.15 & 328.15 \\
\hline Positive electrode (2-sided) & 0.305 & 0.292 & 0.282 & 0.27 & 0.259 \\
\hline Negative electrode (2-sided) & 2.508 & 2.355 & 2.266 & 2.148 & 2.028 \\
\hline & \multicolumn{7}{|c|}{ Specific Heat Capacity / Cp / $\mathrm{kg}^{-1} \mathrm{~K}^{-1}$} \\
\hline Temperature / K & 268.15 & 283.15 & 298.15 & 313.15 & 328.15 \\
\hline Positive electrode (2-sided) & 897 & 925 & 983 & 1057 & 1130 \\
\hline Negative electrode (2-sided) & 585 & 709 & 809 & 892 & 967 \\
\hline & \multicolumn{7}{|c|}{ Thermal Conductivity / W m $\mathrm{m}^{-1}$} \\
\hline Temperature / K & 268.15 & 283.15 & 298.15 & 313.15 & 328.15 \\
\hline Positive electrode (2-sided) & 0.880 & 0.868 & 0.892 & 0.918 & 0.941 \\
\hline NMC811 coating (wetted porous) & 0.796 & 0.785 & 0.807 & 0.830 & 0.851 \\
\hline Negative electrode (2-sided) & 3.249 & 3.696 & 4.058 & 4.243 & 4.339 \\
\hline Graphite-SiOy coating (wetted porous) & 3.037 & 3.455 & 3.793 & 3.967 & 4.056 \\
\hline
\end{tabular}




\section{Effective Thermal Properties}

Lumped thermal models require the effective thermal properties of the jellyroll. The thermal properties of the jellyroll can be measured directly, or they can be calculated using the individual heat capacities of the components. The jellyroll is considered to be a homogenous material so it has a uniform temperature, and the thermal conductivity can be neglected. The jellyroll excludes the casing and the miscellaneous components such as the hard plastic and perforated fibrous membrane at the axial sites. An overall specific heat capacity of $887 \mathrm{~J} \mathrm{~kg}^{-1} \mathrm{~K}^{-1}\left(2.38 \cdot 10^{6} \mathrm{~J} \mathrm{~K}^{-1} \mathrm{~m}^{-3}\right)$ was calculated using the gravimetric contributions and the heat capacities of the individual components in Table 7. The 2-sided electrodes relate to the whole double sided coating, including the current collector and both coated electrodes, whereas the coatings relates to the single sided coating thickness only (not including the current collector). The total specific heat capacity is similar to value reported previously, $850 \mathrm{~J} \mathrm{~kg}^{-1} \mathrm{~K}^{-1}$ for a jellyroll with density $2400 \mathrm{~kg} \mathrm{~m}^{-3} .{ }^{28,44}$

Table 7. Thermophysical properties of the cell components at $25^{\circ} \mathrm{C}$ (measured values are highlighted in green $[\mathrm{m}]$, calculated values in white [c], and literature values in blue [l]).

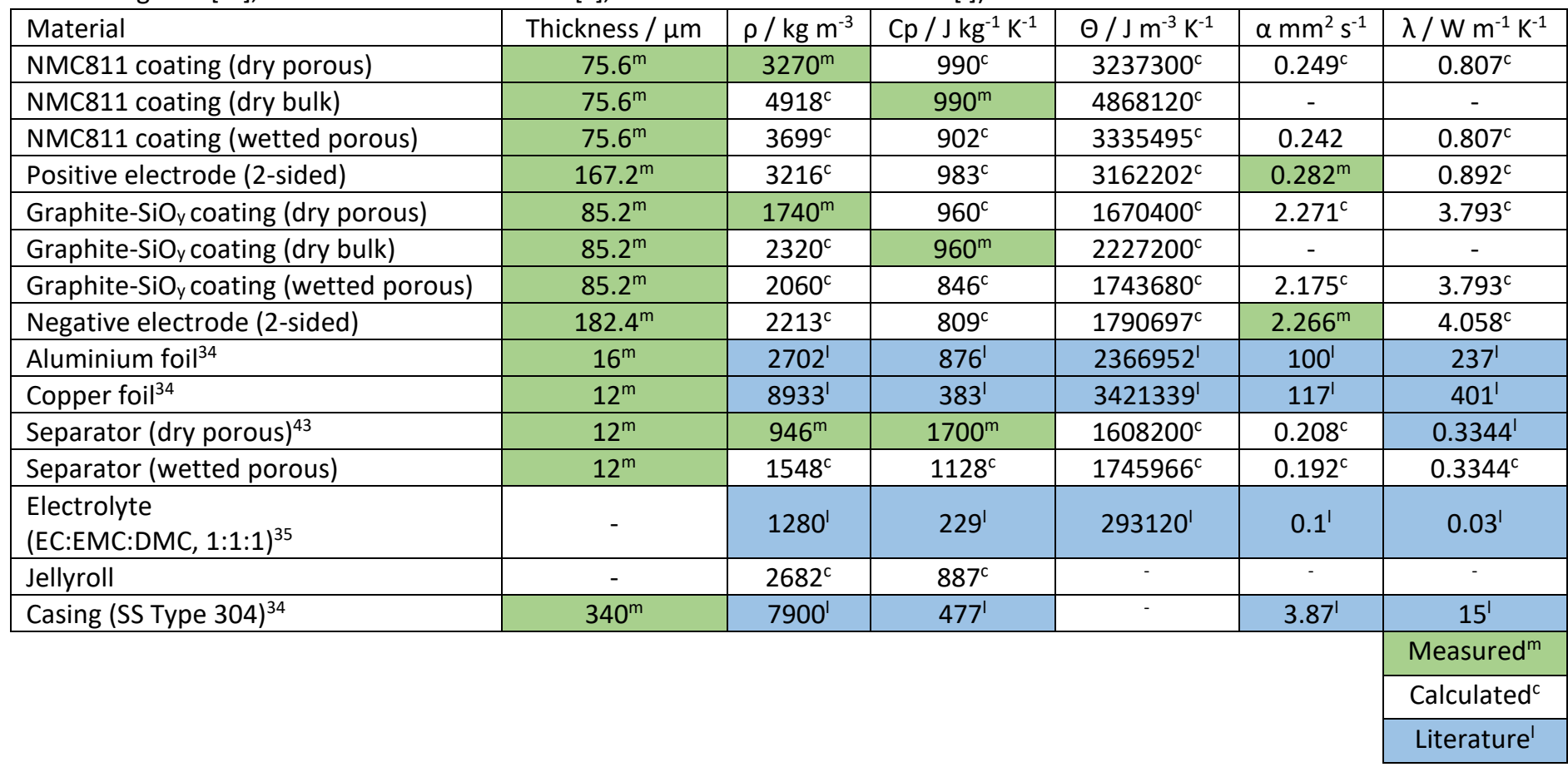

\subsubsection{Thermal-electrochemical Characterisation}

In this section, the temperature dependencies of the parameters were outlined to capture the influence of temperature on electrochemical behaviour, batteries undergo self-heating even at moderate $\mathrm{C}$-rates so this information is essential to accurately predict these changes. These dependencies were modelled using an Arrhenius relationship:

$$
n(T)=n_{r e f} \cdot e^{\frac{E_{n}^{a c t}}{R}\left(\frac{1}{T_{\text {ref }}}-\frac{1}{T}\right)} .
$$

Here $n$ represents a temperature dependent parameter, $n_{\text {ref }}$ is its value at reference temperature namely $T_{r e f}, E_{n}^{a c t}$ is the activation energy, $R$ is the gas constant, and $T$ is the 
temperature in Kelvin. The activation energy can be evaluated by finding the slope $c$ of plot $\ln (n)$ vs. $1 / T$ :

$$
c=E_{n}^{a c t} / R
$$

To describe the heat generation of the cell, the entropic coefficients were measured to capture the reversible heat and the irreversible heat is accounted for in the DFN model definition. The effect of voltage hysteresis is often not considered in models, these properties are therefore evaluated during cell discharge only i.e., positive electrode lithiation and negative electrode delithiation. It has been observed that the hysteresis effect is minimal for parameters including the entropic coefficients and diffusion. ${ }^{23,45}$

The properties are mapped as a function of lithium concentration, the stoichiometric ranges were mapped previously using half-cells. ${ }^{23}$ For the positive electrode this corresponds to crystal lattice lithium concentrations of $x=0.2567$ to 0.9072 and for the negative electrode, $\mathrm{x}=0.0279$ to 0.9014 (Figure 4). However, after a battery is discharged to a specific SOC; electrode stoichiometry varies with time as lithium diffuses in/out of the active materials. To correct for this, the open circuit voltages during the test procedure were aligned to the OCV data (Figure 5). It should be noted, that the capacity of the negative electrode is oversized to the positive electrode for safety, reducing lithium plating and ensuring enough capacity for the lithium removed from the positive electrode. ${ }^{46}$ The positive electrode capacity is not defined by the complete stoichiometric range, but a lithium content which is reversible in the voltage window specified, e.g. $\mathrm{Li}_{x} \mathrm{MO}_{2}$ where $0.26 \leq \mathrm{x} \leq 91$. In this case NMC811 has a practical upper voltage of $4.4 \mathrm{~V} .{ }^{47}$

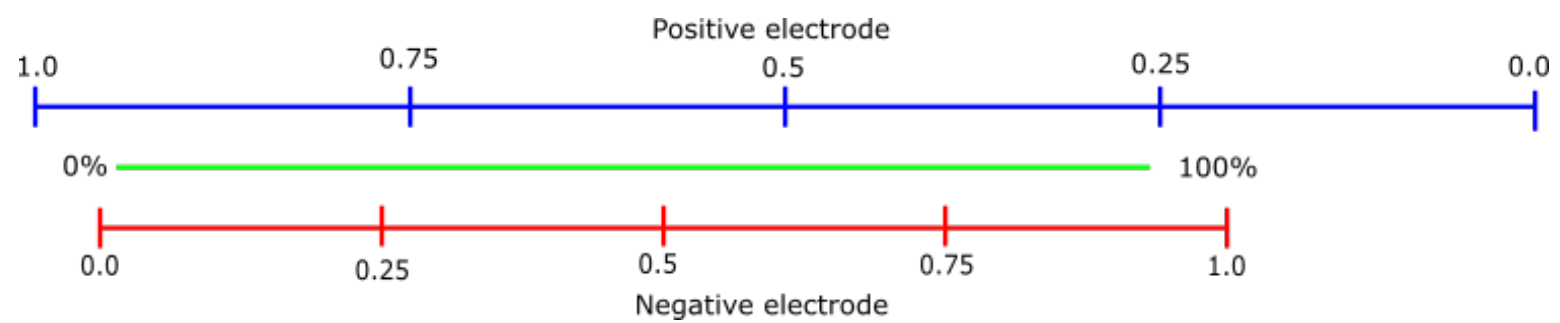

Figure 4. Stoichiometries of the negative (red) and positive electrode (blue) in relation to SOC of the battery (green). 

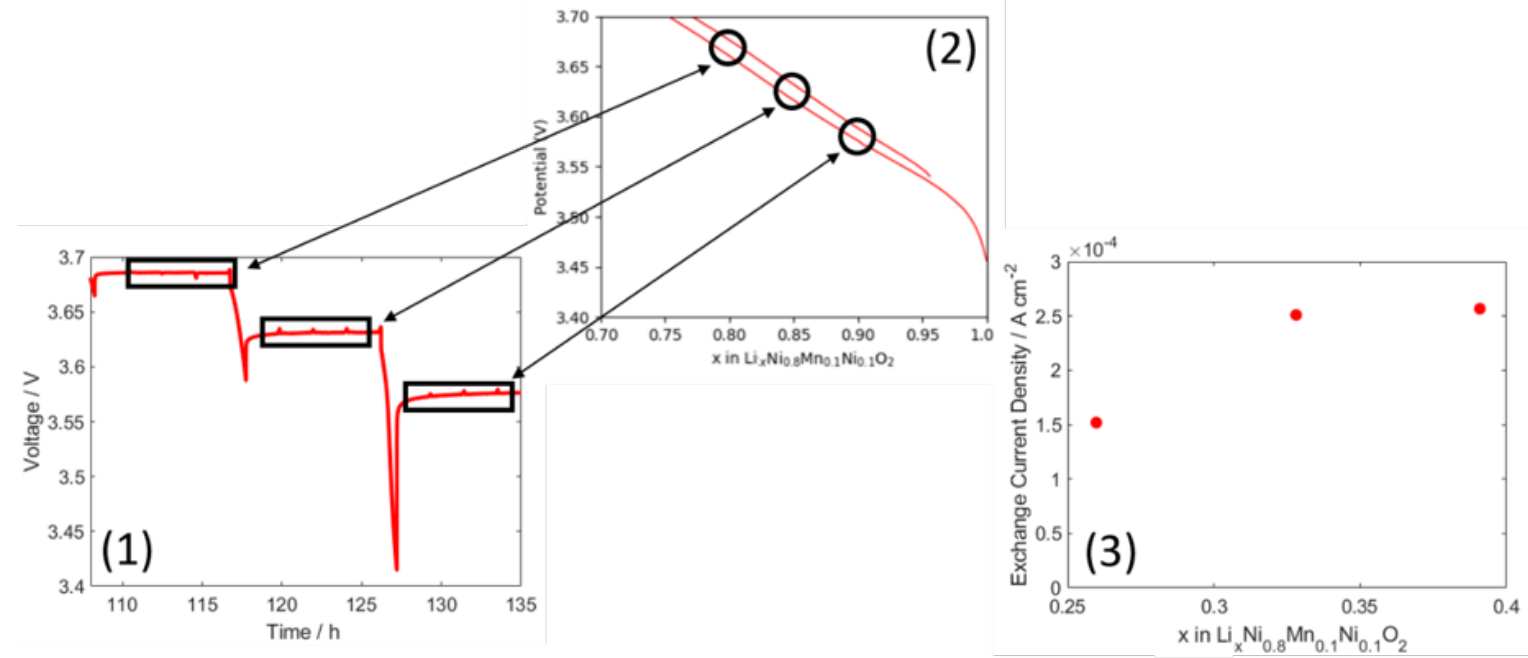

Figure 5. Process to accurately map stoichiometry from test voltage profile and the OCV 'reference' data set. (1) Observe voltage at each point test was carried out e.g., EIS or GITT, (2) find stoichiometry that corresponds to this voltage from OCV profile, and (3) plot parameter vs. determined stoichiometry.

\section{Diffusion}

The activation energy of solid-phase diffusion can be calculated by repeating GITT at different temperatures. ${ }^{18,48}$ This enables us to find the concentration/temperature dependency of solid-phase within the active material. The diffusion coefficients were analysed from the transients and steady-phase regions during GITT. The analytical approach involves evaluating changes in lithium concentration at the particle surface as a function of time. This can be described by an expression relating to the Sand equation: ${ }^{49}$

$$
D_{s}=\frac{4}{\pi}\left(\frac{I}{F S c_{s}^{\max }} \frac{\frac{\partial U}{\partial x}}{\frac{\partial V}{\partial \sqrt{t}}}\right)^{2} .
$$

Here $I$ is the applied current, $F$ is the Faraday constant, $S$ is the effective area of the porous electrode-electrolyte interface, and $c_{S}^{\max }$ is the maximum concentration in the electrode. $S$ can be calculated from the total number of particles in the electrode and the average surface area of a particle:

$$
S=n \cdot S_{\text {particle }}=\frac{\varepsilon_{\text {act }} \cdot V_{\text {electrode }}}{V_{\text {particle }}} S_{\text {particle }}
$$

$\varepsilon_{a c t}$ is the active material volume fraction, $V_{\text {electrode }}$ is the electrode volume, $V_{\text {particle }}$ is particle volume, $S_{\text {particle }}$ is the particle surface area. For this the average particle sizes of $5.22 \mu \mathrm{m}$ and $5.86 \mu \mathrm{m}$ were used for the positive and negative electrode respectively, these parameters were measured previously using SEM. ${ }^{23}$ For the analysis of the positive electrode 
diffusivity it is assumed $S$ remains unchanged as NMC volume expansions is negligible, but for the negative electrode we account for the volume expansion of the graphite-SiO ${ }_{y}{ }^{23,50,51}$ This involves applying a linear scaling factor across the diffusivity to capture the $4 x$ volume expansion across the SOC range of the battery. ${ }^{23}$

The solid-phase diffusion coefficients were measured using GITT in a three-electrode cell comprising of the NMC811 positive electrode and the graphite-SiO $\mathrm{y}_{\mathrm{y}}$ negative electrode (Figure 6). The three-electrode set-up probed a limited stoichiometric range for each electrode, which was near equivalent to that observed under operation in the cylindrical cell. The diffusion coefficients vary significantly with lithium concentration, distinct regions can be identified in these profiles and attributed to distinct thermodynamic phases. ${ }^{52}$ For the NMC-based electrode these phases relate to the different crystal structures of $\mathrm{LiNi}_{0.8} \mathrm{Mn}_{0.2} \mathrm{CO}_{0.2} \mathrm{O}_{2}$ e.g. hexagonal and monoclinic. ${ }^{47,53}$ For graphite-SiO ${ }_{y}$, the $\mathrm{Li}$ insertion stages of graphite are responsible for the changes in solid-phase diffusivity e.g. I to IV. ${ }^{52,54}$ For the temperature range $5{ }^{\circ} \mathrm{C}$ to $45^{\circ} \mathrm{C}$, the diffusivity of the NMC811 was approximately $10^{-10} \mathrm{~cm}^{2} \mathrm{~s}^{-1}$ to $10^{-11} \mathrm{~cm}^{2} \mathrm{~s}^{-1}$ and for graphite-SiO $y$ it was $10^{-14} \mathrm{~cm}^{2} \mathrm{~s}^{-1}$ to $10^{-10} \mathrm{~cm}^{2} \mathrm{~s}^{-1}$, see Figure S4 and S5 respectively for the raw data. The solid-phase diffusion coefficients for graphite-SiO between $10^{-14} \mathrm{~cm}^{2} \mathrm{~s}^{-1}$ to $10^{-12} \mathrm{~cm}^{2} \mathrm{~s}^{-1}$ are underestimates due to difficultly observing the minor voltage changes that occur during the transient and relaxation periods of GITT for the plateau regions in graphite. In plateau regions the reaction overpotentials dominate and produce inaccuracies for the solid-phase diffusivity.

The diffusion coefficients of NMC materials have been reported in the range of $10^{-10} \mathrm{~cm}^{2} \mathrm{~s}^{-1}$ to $10^{-8} \mathrm{~cm}^{2} \mathrm{~s}^{-1}$ previously, corroborating fairy well with the results here. ${ }^{55,56}$ However, the diffusion values for $\mathrm{SiO}_{\mathrm{y}}$ and graphite have had values reported much higher than observed here, between $10^{-11} \mathrm{~cm}^{2} \mathrm{~s}^{-1}$ to $10^{-8} \mathrm{~cm}^{2} \mathrm{~s}^{-1}$ and $10^{-10} \mathrm{~cm}^{2} \mathrm{~s}^{-1}$ to $10^{-8} \mathrm{~cm}^{2} \mathrm{~s}^{-1}$ for the materials respectively. ${ }^{51,57,58}$ Diffusion coefficients are often reported over several orders of magnitude due to differences in experimental set-ups and analysis. The solid-phase diffusivity often has to be tuned to a higher value for to provide reasonable simulation values as if the low diffusivity values are included in the fits, the simulations either do not converge or provide unrealistic results. This tuning was carried out here and the fitted profiles are illustrated in Figure 6.

Equation [10] was used to account for the dependency of solid-phase diffusivity on stoichiometry, this equation is illustrated in Figure 6 . The equation is a linear combination of Gaussian functions and captures the features of the profile accurately, meaning non-linear solid-phase diffusivity can be captured by the simulations (the fitting parameters can be found in Table S7):

$$
\begin{aligned}
\log _{10} D_{s}(x)= & a_{0} \cdot x+b_{0}+c_{0}+a_{1} \cdot \exp \left(-\frac{\left(x-b_{1}\right)^{2}}{c_{1}}\right)+a_{2} \cdot \exp \left(-\frac{\left(x-b_{2}\right)^{2}}{c_{2}}\right) \\
& +a_{3} \cdot \exp \left(-\frac{\left(x-b_{3}\right)^{2}}{c_{3}}\right)+a_{4} \cdot \exp \left(-\frac{\left(x-b_{4}\right)^{2}}{c_{4}}\right) .
\end{aligned}
$$


These fits are later used in the model and shown in Figure S4 and S5. Figure 6 also describes the change in diffusivity across the measured stoichiometric range as a function of temperature, demonstrating the Arrhenius-type behaviour of this parameter. The average value of solid-phase diffusivity of the 'fitted' curves for the graphite-SiO $\mathrm{y}$ is lower than the experimental average for about a factor of three, because we are fitting to the $\log _{10}(D)$ rather than $D$. The reason not to fit to $D$ directly is because that would not capture the features in low diffusivity zones, plus adds the risk of obtaining negative values for diffusivity. Fitting to to the $\log _{10}(D)$ ensures diffusivity is always positive and captures the features at different orders of magnitude, at the expense of underestimating the average diffusivity (especially in the negative electrode). Therefore, a scaling factor of 3.03 for the graphite-SiO $\mathrm{O}_{\mathrm{y}}$ diffusivity was introduced in the diffusivity used in the final model so the fitted average diffusivity matched the experimental average diffusivity across all temperatures, as shown in Figure 6 (bottom right).
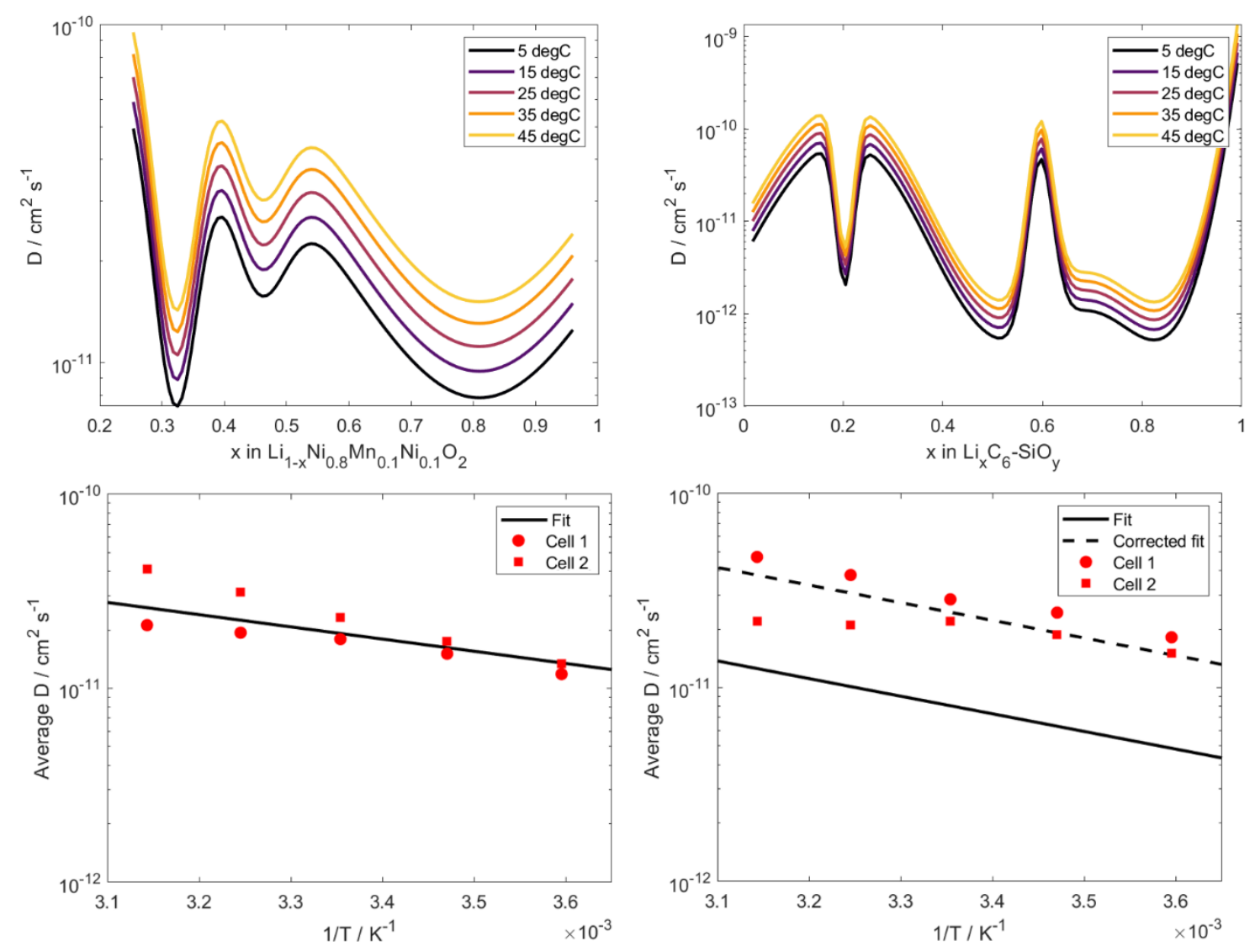

Figure 6. Fitted solid-phase diffusivity values of NMC811 positive electrode (top left) and the graphite-SiO $y$ negative electrode (top right) as a function of stoichiometry and temperature. Arrhenius dependency for the average solid-phase diffusivity of NMC811 positive electrode (bottom left) and the graphite- $\mathrm{SiO}_{y}$ negative electrode (bottom right) as a function of temperature.

An Arrhenius relationship (Eq. [6]) can be used to find the activation energies across the stoichiometric range of each electrode (Figure 7). Similarly to the solid-phase diffusivity, the activation energies are influenced by thermodynamic phases and their transitions. For NMC 
the activation energy is in the range of $10 \mathrm{~kJ} \mathrm{~mol}^{-1}$ to $20 \mathrm{~kJ} \mathrm{~mol}^{-1}$. This compares to reported values of $15 \mathrm{~kJ} \mathrm{~mol}^{-1}$ to $30 \mathrm{~kJ} \mathrm{~mol}^{-1}$ for the lower nickel content $\mathrm{NMC}$ electrodes. ${ }^{59}$ For graphite-SiO the activation energy has a wider range of $5 \mathrm{~kJ} \mathrm{~mol}^{-1}$ to $60 \mathrm{~kJ} \mathrm{~mol}^{-1}$. Similar to values up to $50 \mathrm{~kJ} \mathrm{~mol}^{-1}$ for graphite reported by Ecker et al. ${ }^{16}$ For graphitic materials the consensus is that values are generally between $20 \mathrm{~kJ} \mathrm{~mol}^{-1}$ and $40 \mathrm{~kJ} \mathrm{~mol}^{-1} .60-62$ The range in reported values is attributed to the variability and high uncertainty for the analytical approaches used in determining the diffusion coefficients. ${ }^{52}$ Significant temperature dependence is observed for the diffusivity between stoichiometries of $x=0.3$ to 0.5 and at approximately $\mathrm{x}=0.8$, corresponding to the plateau regions of graphite.
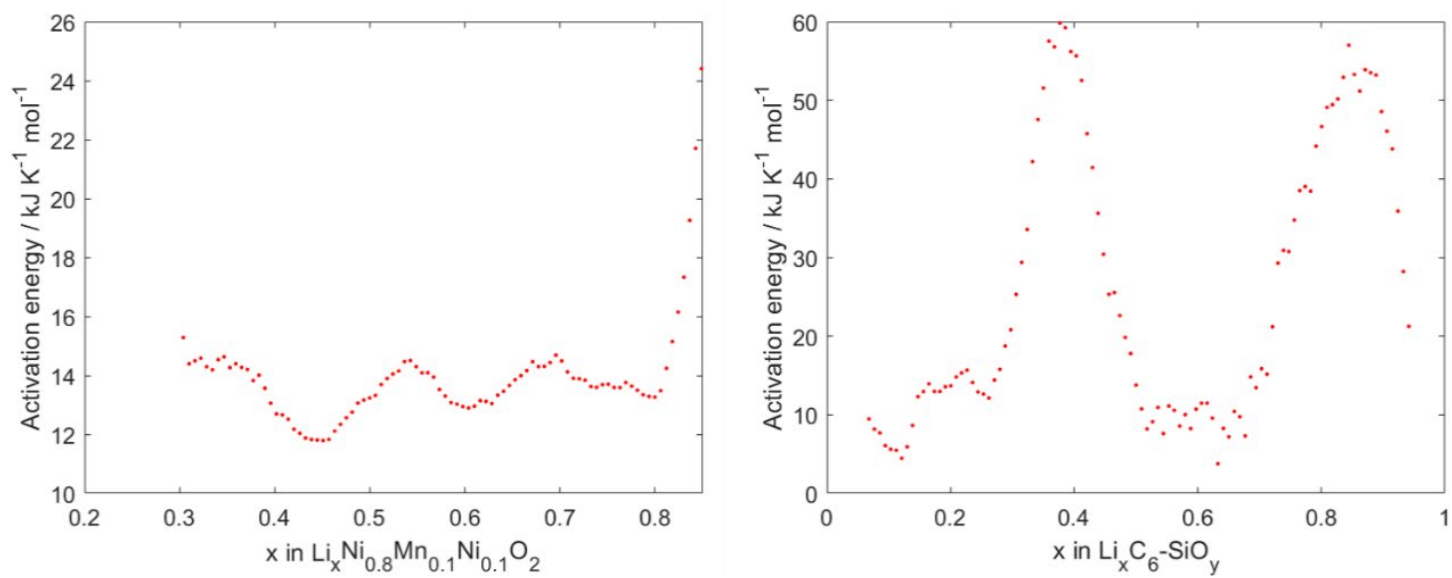

Figure 7. The solid-phase diffusivity activation energies for the NMC-based (left) and graphite-SiO (right) electrodes measured in a three-electrode configuration

\section{Exchange Current}

Previously the exchange current density and its activation energy were evaluated at a single stoichiometry. ${ }^{23}$ Here, the exchange current density and its dependency were mapped on temperature and lithium concentration at various stoichiometries using a half cell (Figure 9). The exchange current density $j_{o}$ can be evaluated by measuring the charge-transfer resistance $R_{c t}$ during EIS:

$$
R_{c t}=\frac{R T}{j_{o} S F}
$$

Here $R, S$, and $F$ are the gas constant, the electrode-electrolyte interfacial area, and the Faradaic constant. For these calculations $S$ was calculated from the geometrical electrode volume $V$, the active material volume fraction $\varepsilon_{a c t}$, and particle radius:

$$
S=\frac{3 \varepsilon_{a c t}}{r} V
$$

This was determined to be $3.266076 \cdot 10^{-3} \mathrm{~m}^{2}$ and $4.151297 \cdot 10^{-3} \mathrm{~m}^{2}$ for the positive and negative electrode respectively. The Nyquist plot for the positive electrode only shows one semi-circle that can be attributed to the charge transfer process. This is because the SEI 
resistance shares a similar time constant with the double layer and therefore is difficult to visually discern the phenomena (see Figure S6). However, two RC elements should be included in the equivalent circuit model to account for the charge transfer and SEI resistance. The Nyquist plots are fitted to an equivalent circuit model (Figure 8) to evaluate $R_{c t}$ and then used to determine $j_{o}$ from Eq. [11].

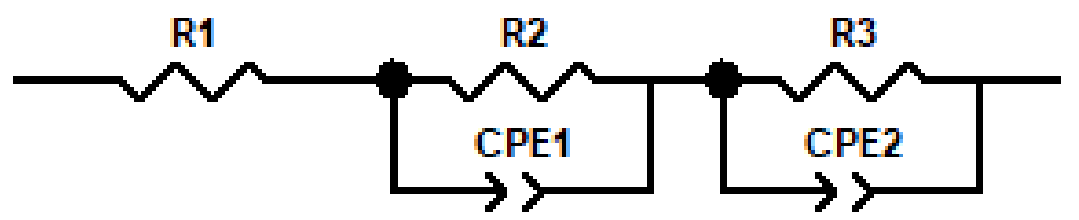

Figure 8. Equivalent circuit model used for fitting. $(R=$ resistor and $C P E=$ constant phase element.

The exchange current density demonstrates a dependency on lithium concentration that can be described by a form of the Butler-Volmer equation (see Figure 9): ${ }^{16}$

$$
j_{0}=k_{0} \cdot\left(1-\frac{c_{s}}{c_{s, \max }}\right)^{1-\alpha} \cdot\left(\frac{c_{s}}{c_{s, \max }}\right)^{\alpha} \cdot\left(\frac{c_{e}}{c_{e 0}}\right)^{1-\alpha} .
$$

Here $c_{s}$ and $c_{e}$ refer to lithium concentration in the solid lattice and electrolyte, respectively, $c_{s, \max }$ is the maximum concentration in the electrode particles and $c_{e 0}$ is the reference concentration in the electrolyte. The parameter $k_{0}$ is the reference current of the reaction. As shown in Figure 9, the exchange current density for the NMC811 positive electrode was measured at $25{ }^{\circ} \mathrm{C}$ between $0.5 \cdot 10^{-4} \mathrm{~A} \mathrm{~cm}^{-2}$ and $3.0 \cdot 10^{-4} \mathrm{~A} \mathrm{~cm}^{-2}$ with a mean value of $2.01 \cdot 10^{-4} \mathrm{~A} \mathrm{~cm}^{-2}$. For the graphite-SiO electrode the exchange current density was measured at $25^{\circ} \mathrm{C}$ between $2.0 \cdot 10^{-5} \mathrm{~A} \mathrm{~cm}^{-2}$ and $9.0 \cdot 10^{-5} \mathrm{~A} \mathrm{~cm}^{-2}$ with a mean value of $7.1 \cdot 10^{-5} \mathrm{~A} \mathrm{~cm}^{-2}$. The observed trends are similar to the results reported by Ecker et al. who reported a value of 2.23.10-4 $\mathrm{A} \mathrm{cm}^{-2}$ and $7.0510^{-5} \mathrm{~A} \mathrm{~cm}^{-2}$ corresponding to $\mathrm{x}=0.5$ in $\mathrm{Li}_{\mathrm{x}}\left(\mathrm{Ni}_{0.4} \mathrm{CO}_{0.6}\right) \mathrm{O}_{2}$ and $\mathrm{Li}_{\mathrm{x}} \mathrm{C}_{6}{ }^{16}{ }^{16} \mathrm{The}$ Butler-Volmer equation (Eq. [13]) fits the negative electrode exchange current density vs stoichiometry well, this fit is worse for the positive electrode $\left(R^{2}=0.63\right)$ and a semi-ellipse with an exchange current value of 0 at stoichiometries at $\sim 0.2$ and 0.9 (at $25^{\circ} \mathrm{C}$ ) provides a better fit $\left(R^{2}=0.9\right.$, Fig S7). The question arises whether using the stoichiometry of 0 to 1 to represent degree of lithiation with respect to the molar lithium concentration within the crystal structure is the correct assumption to use in the model. There is most probably 'inactive' or non-mobile lithium below $x=0.2$ in this case as observed in Figure 9, where it is impractical for $\mathrm{Li}_{x} \mathrm{Ni}_{0.8} \mathrm{Mn}_{0.1} \mathrm{CO}_{0.1} \mathrm{O}_{2}$ to be delithiated further due to collapse of the crystal structure. ${ }^{47}$ There is little sensitivity in this particular parameter, ${ }^{63}$ and therefore have assumed Butler-Volmer kinetics over the entire lithium stoichiometry in this work which is consistent with the model inputs.

The activation energy of the exchange current density was evaluated using an Arrhenius relationship (Equation [6]) across the stoichiometric range of each electrode (Figure 10). The activation energies for the positive electrode range between $20 \mathrm{~kJ} \mathrm{~mol}^{-1}$ to $50 \mathrm{~kJ} \mathrm{~mol}^{-1}$ and for 
the negative electrode between $45 \mathrm{~kJ} \mathrm{~mol}^{-1}$ to $65 \mathrm{~kJ} \mathrm{~mol}^{-1}$. The mean values for the $\mathrm{Ni}$-rich and graphite based electrodes were $31.1 \mathrm{~kJ} \mathrm{~mol}^{-1}$ and $54.8 \mathrm{~kJ} \mathrm{~mol}^{-1}$ respectively. Ecker et al. reported activation energies of $43.6 \mathrm{~kJ} \mathrm{~mol}^{-1}$ for $\mathrm{Li}\left(\mathrm{Ni}_{0.4} \mathrm{CO}_{0.6}\right) \mathrm{O}_{2}$ and $53.4 \mathrm{~kJ} \mathrm{~mol}^{-1}$ for graphite. ${ }^{16}$ Jow et al. reported activation energies for graphite and NCA as $68 \mathrm{~kJ} \mathrm{~mol}^{-1}$ and $50 \mathrm{~kJ} \mathrm{~mol}^{-1}$ respectively. ${ }^{64}$ Smart et al. reported activation energies for graphite and $\mathrm{Li}\left(\mathrm{Ni}_{0.8} \mathrm{Co}_{0.2}\right) \mathrm{O}_{2}$ with different electrolyte systems in the ranges $45 \mathrm{~kJ} \mathrm{~mol}^{-1}$ to $60 \mathrm{~kJ} \mathrm{~mol}^{-1}$ and $-34 \mathrm{~kJ} \mathrm{~mol}^{-1}$ to $48 \mathrm{~kJ} \mathrm{~mol}^{-1} .65$ Similar ranges have been reported for graphite and $\mathrm{Li}\left(\mathrm{Ni}_{0.5} \mathrm{Mn}_{0.3} \mathrm{Co}_{0.2}\right) \mathrm{O}_{2}$, these were $56 \mathrm{~kJ} \mathrm{~mol}^{-1}$ to $72 \mathrm{~kJ} \mathrm{~mol}^{-1}$ and $58 \mathrm{~kJ} \mathrm{~mol}^{-1}$ to $69 \mathrm{~kJ} \mathrm{~mol}^{-1} .66$

Previously reported values for this cell was $17.8 \mathrm{~kJ} \mathrm{~mol}^{-1}$ and $35 \mathrm{~kJ} \mathrm{~mol}^{-1}$ for NMC and graphite respectively. ${ }^{23}$ However, these activation energies are appreciably lower than the values reported here and for similar materials. In this case, the parameter table is updated with the newly evaluated activation energies that have been measured at various lithium stoichiometries and corroborate with literature. The dependency of the exchange current density on temperature and lithium concentration can be described as:

$$
\begin{gathered}
j_{0}(c, T)=k_{0} \cdot\left(1-\frac{c_{s}}{c_{s, \max }}\right)^{1-\alpha} \cdot\left(\frac{c_{s}}{c_{s, \max }}\right)^{\alpha} \\
\cdot\left(\frac{c_{e}}{c_{e 0}}\right)^{1-\alpha} \exp \left(-\frac{E_{a}}{R} \cdot\left(\frac{1}{T}-\frac{1}{298.15}\right)\right) .
\end{gathered}
$$

Here $k_{0}$ is the reference current, $\alpha$ is the activity coefficient, and $E_{a}$ is the activation energy; and the variables are the stoichiometry and temperature. Because the stoichiometry is defined as $x=\frac{c_{s}}{c_{s, \max }}$, this equation combines Butler-Volmer (Eq. [13]) and Arrhenius behaviours (Eq. [6]). These values are outlined in Table S8.
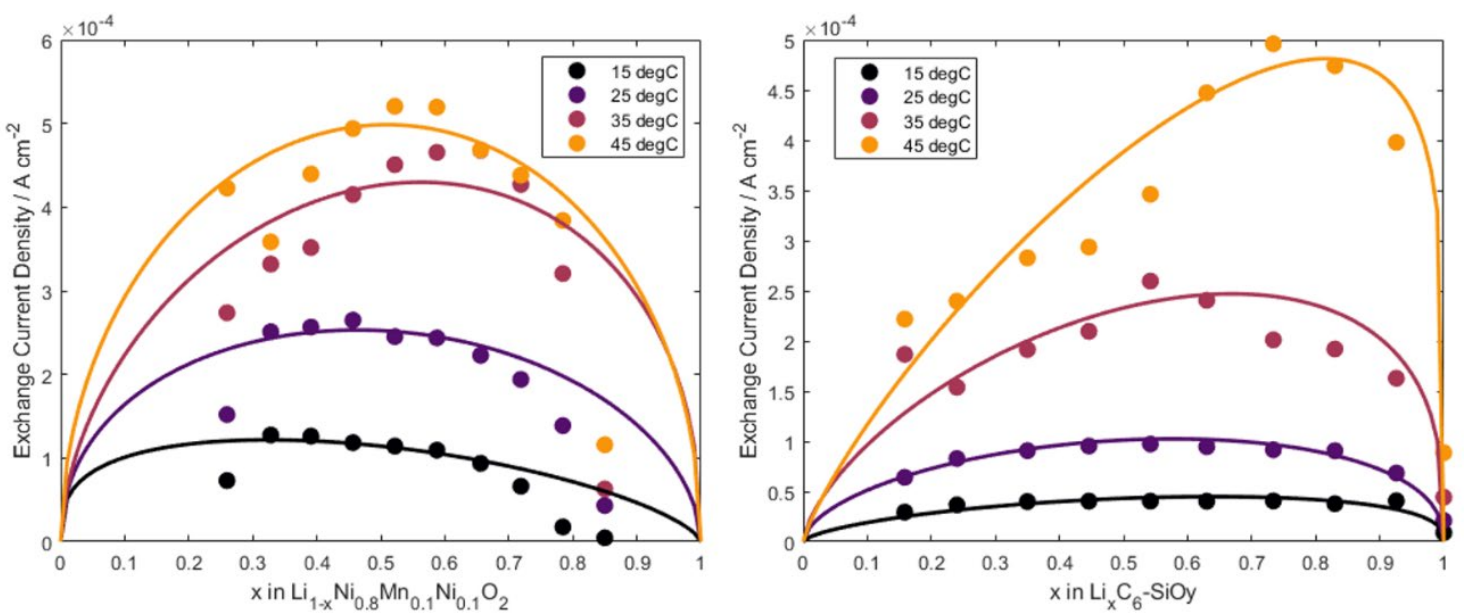

Figure 9. Exchange current density as a function of lithium concentration for the NMC811 positive (left) and graphite-SiO ${ }_{y}$ negative electrode (right) evaluated at $15{ }^{\circ} \mathrm{C}, 25^{\circ} \mathrm{C}, 35^{\circ} \mathrm{C}$, and $45^{\circ} \mathrm{C}$. 

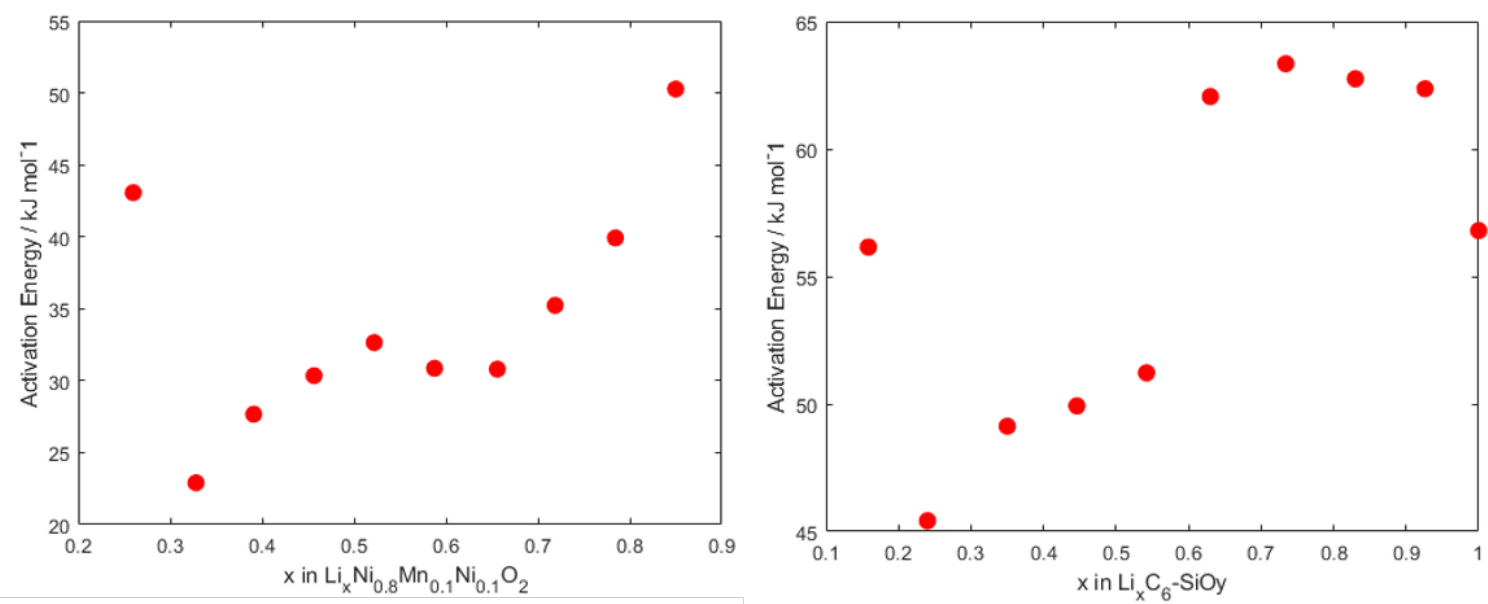

Figure 10. Exchange current density activation energy as a function of lithium concentration for the positive (left) and negative electrode (right).

\section{Electronic Conductivity}

The electronic conductivity is also a temperature-dependent process, however intrinsic material properties determine whether there is a corresponding activation energy. The semi-metallic properties of graphite relate to an inversely proportional relationship with temperature and electronic conductivity. However, in the normal operating temperature range of a battery, the change in graphite electronic conductivity is considered negligible. In contrast, NMC exhibits semiconducting properties (owing to its non-zero band gap energy) this causes electron conduction to be significant dependent on temperature. As the electron conduction in NMC is a thermally activated process the corresponding activation energy can be evaluated using an Arrhenius type relationship (Equation [6]). ${ }^{67}$

The NMC811 electrode was extracted from a cell that was discharged to $2.5 \mathrm{~V}$. This relates to a lithium content of approximately $x=0.9$. At this state of lithiation, the solid-phase electronic conductivity was evaluated to be $0.847 \mathrm{~S} \mathrm{~m}^{-1}$ at $25{ }^{\circ} \mathrm{C}$. This value is four times higher than the $0.18 \mathrm{~S} \mathrm{~m}^{-1}$ activation energy calculated by Chen et al., demonstrating that using liquid gallium to delaminate the electrode rather than adhesive tape preserves the electrode structure. The corresponding activation energy for the positive electrode electronic conductivity was determined to be $3.5 \mathrm{~kJ} \mathrm{~mol}^{-1}$ (Figure 11). The effect of lithium concentration was not evaluated due to the stability of the partially lithiated NMC materials in ambient conditions. Elsewhere, this relationship has been investigated previously by Amin et al. by pelletizing the pure active material and conducting EIS measurements in an electrochemical cell. ${ }^{56}$

Amin et al. studied NMC532 and NMC111 at lithium stoichiometries between $\mathrm{x}=0.25$ and $x=1.0 .{ }^{56}$ For these materials the activation energy of the electronic conductivity decreased from $40 \mathrm{~kJ} \mathrm{~mol}^{-1}$ to $4.8 \mathrm{~kJ} \mathrm{~mol}^{-1}$ and $46.3 \mathrm{~kJ} \mathrm{~mol}^{-1}$ to $9.6 \mathrm{~kJ} \mathrm{~mol}^{-1}$ respectively. The latter values for the lithiated materials are similar to the value reported in this paper. For states of lithiation below $x=0.25$ the material exhibits metallic properties and electronic conduction is not thermally activated. The electronic conductivity is the least sensitive parameter in the DFN model and therefore it is less critical to describe its dependency on lithium concentration. 


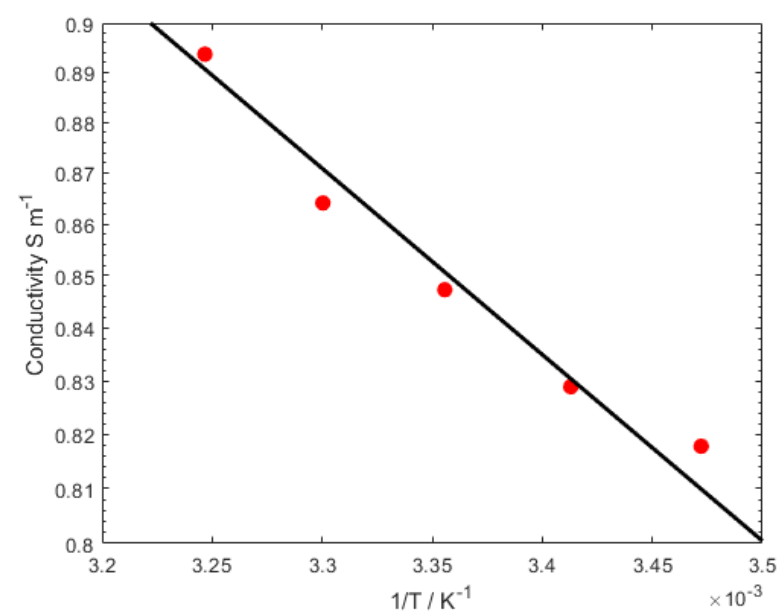

Figure 11. Electronic conductivity evaluated for NMC811 extracted from a fully discharged cell. This corresponds to a lithium stoichiometry of approximately $x=0.9$. These values are plotted versus the inverse of temperature for the positive electrode. The gradient provides the activation energy for NMC.

\section{Entropic Term}

There are several sources of heat generation in batteries. ${ }^{37}$ The irreversible and reversible heat components are considered important as the active materials' dominating heat generation. ${ }^{68}$ For high C-rates (most scenarios) more than half of the heat generation can be ascribed to irreversible heat, known as ohmic heat loss. ${ }^{69}$ At low C-rates (1C or less) the reversible heat contribution from the material phase changes becomes more significant, this heat generation is due to the entropy changes that occur as a result of intercalation reactions, and this property depends on the internal temperature and OCV of the system. The entropy change can account for over half the total heat generated at the rates typically used in electric vehicles. ${ }^{70,71}$ Parameterisations that outline activation energies do not characterise the reversible heat of the battery, this is important to predict temperature and the influenced electrochemical performance correctly. ${ }^{16,18}$

The change in entropy $\Delta S$ can be determined through the slope of the OCV with temperature: ${ }^{72}$

$$
\Delta S=\frac{-\Delta G}{T}=n F\left(\frac{E}{T}\right)
$$

The entropic term is measured using a potentiostatic method which involves measuring the dependency of OCV on temperature (Figure 12). ${ }^{73}$ The temperature is changed three times at each lithium concentration. This provides four OCVs at the different temperatures; the entropic term can be calculated from the gradient of a line through the points. This process is repeated to map the stoichiometric range of the electrodes. It can take many hours to attain OCV at a particular SOC and temperature, therefore the thermal stability of the electrolyte needs to be considered when choosing the temperature regime. This is because at high temperatures due to electrochemical instability, particularly at the graphite interface, it is 
more difficult to attain OCV. ${ }^{74}$ Choosing a lower temperature regime avoids instabilities, while allowing the thermodynamic behaviour to be measured.
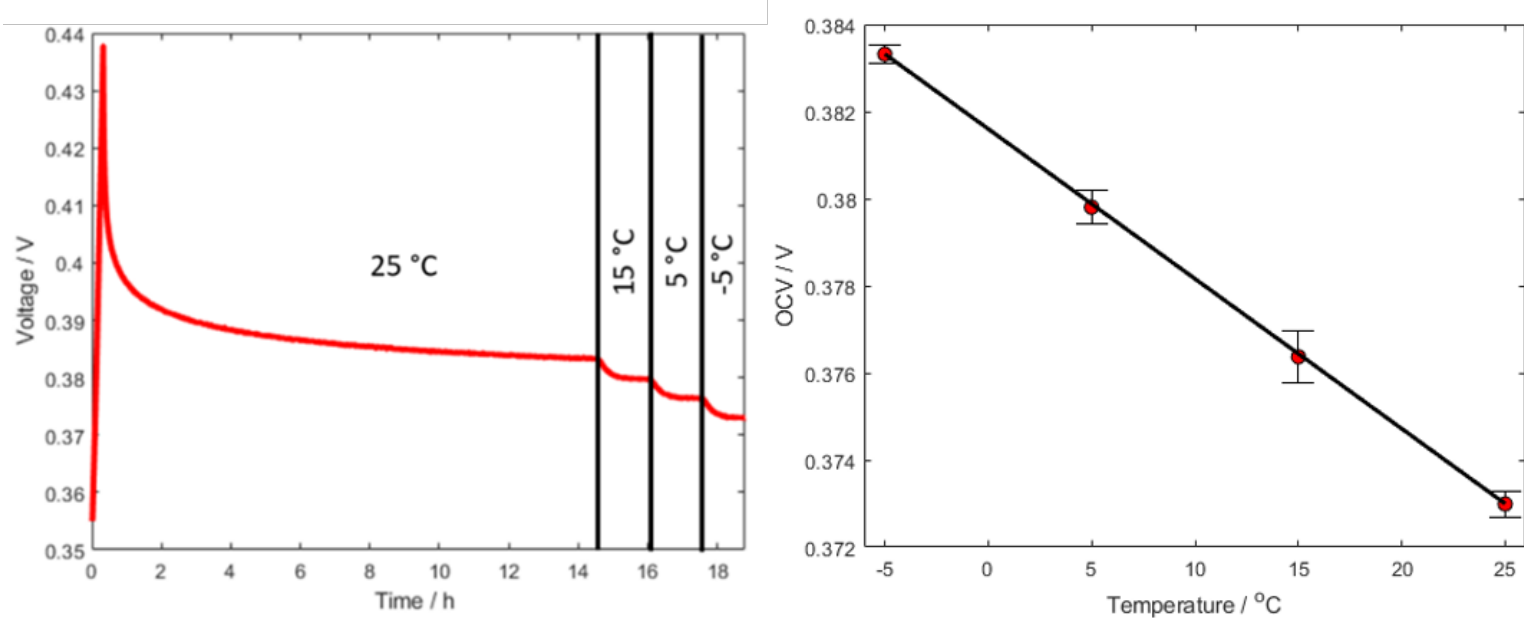

Figure 12. Potentiometric profile illustrating the initial SOC change, followed by a long period to attain OCV and a temperature-cycling regime to observe voltage change (left). The entropic term is calculated from the gradient of the OCV points at each temperature (right).

Using a three-electrode configuration for the experiment allows us to measure the entropic terms for SoCs between $0 \%$ and $100 \%$, see Figure 13 . This means that the entropic term for both electrodes is mapped at the same SOCs for both electrodes. At low states of lithiation the graphite OCV decreases as temperature increases, this corresponds to a $\Delta S<0$. As the graphite electrode is delithiated the entropic term becomes positive. This change occurs at $x=0.6$. These observations agree with research by Reynier et al. on a pure graphite electrode. ${ }^{75}$ This suggests that less than $10 \mathrm{wt} \%$ of $\mathrm{SiO}_{\mathrm{y}}$ has a minimal effect on the entropic term. This results are also consistent with the entropic term of a silicon-graphite material that was reported for lithium stoichiometries less than $0.7 .^{76}$

The entropic term of the NMC electrode is negligible at several states of lithiation. For the other states of lithiation it does not show an appreciable value. This means the full cell behaviour is dominated by the negative electrode and the trend is the same, although the opposite magnitude. This is due to the definition of the full cell potential $\left(E_{c e l l}=E_{w e}-E_{c e}\right)$. The reversible heat generation in the cell is determined by the graphite-based electrode. These values are in good agreement with published results; the entropic term of NMC-type electrodes have been shown to be negligible in comparison to other positive electrode chemistries. ${ }^{71}$

The variation of entropic term with stoichiometry has been captured by fitting functions to the experimental data. For the negative and positive electrode these functions are (fitting parameters outlined in Table S9):

$$
\begin{gathered}
\frac{\partial U_{\mathrm{p}}}{\partial T}(x)=a_{1} \cdot \exp \left(-\frac{\left(x-b_{1}\right)^{2}}{c_{1}}\right)+a_{2} \cdot \exp \left(-\frac{\left(x-b_{2}\right)^{2}}{c_{2}}\right), \\
\frac{\partial U_{\mathrm{n}}}{\partial T}(x)=a_{0} \cdot x+b_{0}+a_{1} \cdot \exp \left(-\frac{\left(x-b_{1}\right)^{2}}{c_{1}}\right)
\end{gathered}
$$


However, the function for the negative electrode entropic term was chosen to exclude the points at intermediate stoichiometries. This is because including these points inadequately describes heat generation at $0.5 \mathrm{C}$, see Figure 14 . This is despite the values reported here being similar as previously reported for this material, it is not clear why a discrepancy arises when the negative entropic coefficients for the negative electrode are included. ${ }^{22}$
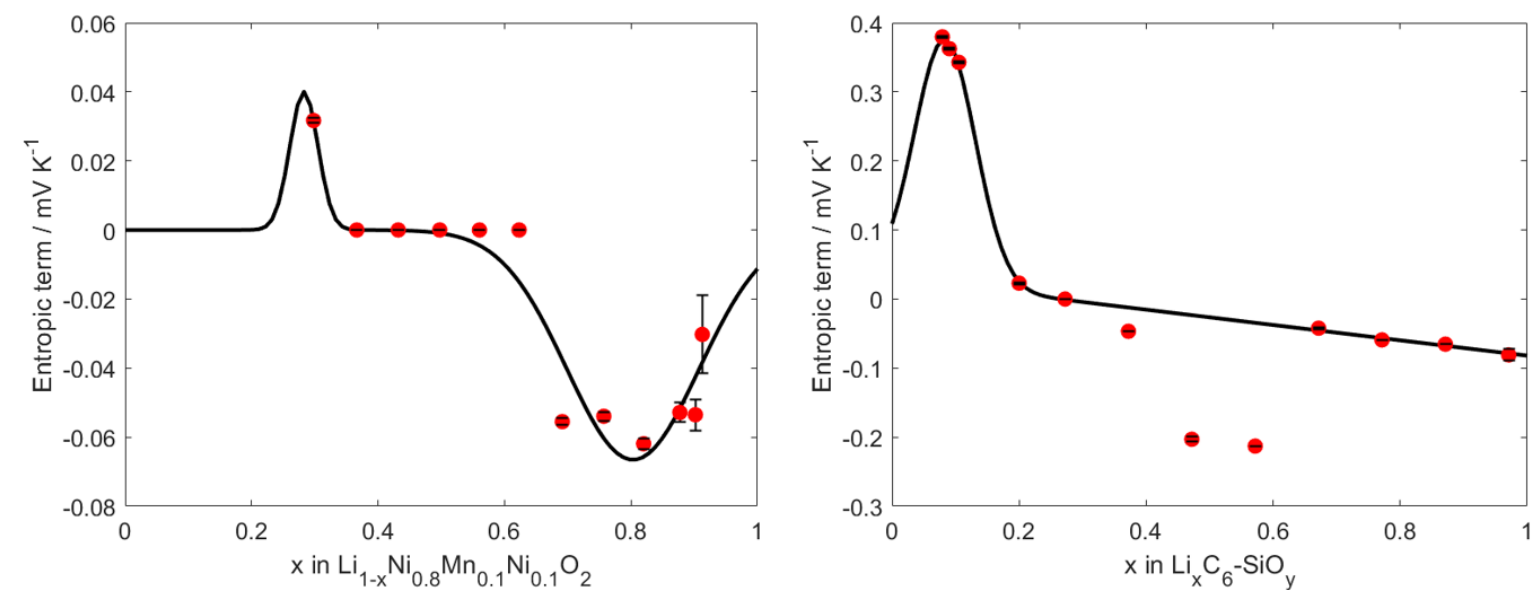

Figure 13. Entropic term and polynomial fits for the negative electrode (left) and positive electrode (right).
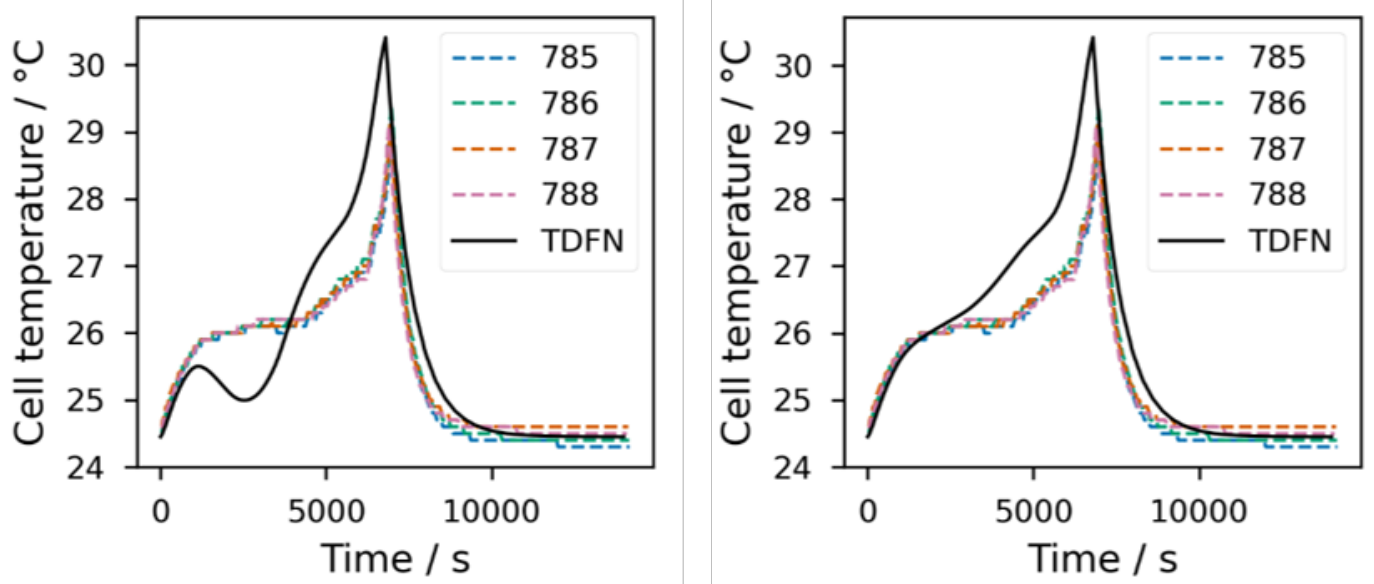

Figure 14. Experimental and simulated temperature profiles with the negative electrode entropic term including all data points (left) and excluding the intermediate data points (right). The experimental data was from tests on four cylindrical cells (the cell ID numbers are listed in the legend), while the simulated data was using the fully parameterised DFN model. This data was for a cylindrical cell discharge of $0.5 \mathrm{C}$ at $25^{\circ} \mathrm{C}$.

This term has been represented by high order even polynomial functions in the past, however this fitting is often inadequate outside the stoichiometric range. ${ }^{77}$ It is difficult to predict the entropic term value outside the measured range, for this reason it is assumed the parameter tends to zero, rather than assigning it a non-zero value that may overestimate heat generation. 
This section provides the information needed to construct an accurate thermally-coupled electrochemical model by outlining the activation energies and the reversible heat of the battery. This information is often not measured in parameterisations and is critical to predicting the internal temperature and its influence on thermal performance. ${ }^{16,17}$ The methodologies also describe the experimental and mathematical approach to quantify the parameter-dependencies of several electrochemical parameters, enabling the changes in performance during battery operation to be documented. The methods can be applied similarly to the widely-used materials, graphite and NMC.

\section{Electrolyte Properties}

lon-transport models for concentrated binary electrolyte solutions depend on the ionic conductivity, ionic diffusivity, and the transference number. ${ }^{78}$ The thermodynamic factor (TDF) is also required to describe the thermodynamic behaviour of the electrolyte system, this parameter is dependent on the mean molar activity coefficient. To be consistent with the electrochemical parameterization of this cell it is assumed the electrolyte was $1 \mathrm{~mol} \mathrm{dm}^{-3} \mathrm{LiPF}_{6}$ in EC:EMC $(3: 7, \mathrm{v}: \mathrm{v}) .{ }^{23}$ This was assumed to the difficulty determining the electrolyte composition.

The temperature and concentration dependence of the electrolyte properties has been determined previously by Gasteiger et al. ${ }^{79}$ The dependencies for the ionic conductivity, ionic diffusivity, thermodynamic factor, and the transference number can be described as the following empirically-derived relationships:

$$
\begin{gathered}
\kappa(T, c)=p_{1} \cdot\left(1+\left(T-p_{2}\right)\right) \cdot \frac{\left(1+p_{3} \cdot \sqrt{c} \cdot p_{4} \cdot\left(1+p_{5} \cdot \exp \left(\frac{1000}{T}\right)\right)\right.}{1+c^{4} \cdot\left(p_{6} \cdot \exp \left(\frac{1000}{T}\right)\right)} \frac{\mathrm{ms}}{\mathrm{cm}} . \\
D_{ \pm}(T)=p_{1} \cdot \exp \left(p_{2} \cdot c\right) \cdot \exp \left(\frac{p_{3}}{T}\right) \cdot \exp \left(\frac{p_{4}}{T} \cdot c\right) \cdot 10^{-6} \frac{\mathrm{cm}^{2}}{\mathrm{~s}} . \\
T D F(T)=p_{1}+p_{2} \cdot c+p_{3} \cdot T+p_{4} \cdot c^{2}+p_{5} \cdot T+p_{6} \cdot T^{2}+p_{7} \cdot c^{3} \\
+p_{8} \cdot c^{2}+p_{9} \cdot c \cdot T^{2} \\
t_{+}(T)=p_{1}+p_{2} \cdot c+p_{3} \cdot T+p_{4} \cdot c^{2}+c \cdot p_{5} \cdot T+p_{6} \cdot T^{2}+p_{7} \cdot c^{3} \\
+p_{8} \cdot c^{2}+p_{9} \cdot c \cdot T^{2}
\end{gathered}
$$

The fitting parameters values $p_{i}$ have been outlined elsewhere. ${ }^{79}$ These functions have been previously included in the PyBaMM software used for the simulations. 
Table 8. Parameters used in our thermal-electrochemical simulations. *Thermophysical properties of wetted components, blue $=$ parameters tuned to obtain agreement for $1 \mathrm{C}$ discharge at $25^{\circ} \mathrm{C}$.

\begin{tabular}{|c|c|c|c|c|c|}
\hline & Parameter & Unit & $\begin{array}{c}\text { Positive electrode } \\
(k=p)\end{array}$ & $\begin{array}{c}\text { Separator } \\
(k=\mathrm{s})\end{array}$ & $\begin{array}{c}\text { Negative electrode } \\
\quad(k=\mathrm{n})\end{array}$ \\
\hline \multirow{20}{*}{ 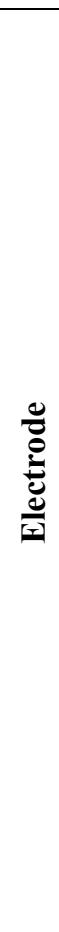 } & Active material type & & $\mathrm{LiNi}_{1-\mathrm{x}-\mathrm{y}} \mathrm{Mn}_{\mathrm{x}} \mathrm{Co}_{\mathrm{y}} \mathrm{O}_{2}$ & $\begin{array}{c}\text { Ceramic coated } \\
\text { polyolefin }\end{array}$ & Graphite $+\mathrm{SiO}_{\mathrm{y}}$ \\
\hline & Current collector thickness & $\mathrm{m}$ & $16 \cdot 10^{-6}$ & - & $12 \cdot 10^{-6}$ \\
\hline & Electrode thickness $\left(L_{k}\right)$ & $\mathrm{m}$ & $75.6 \cdot 10^{-6}$ & $12 \cdot 10^{-6}$ & $85.2 \cdot 10^{-6}$ \\
\hline & Mean particle radius $\left(R_{k}\right)$ & $\mathrm{m}$ & $5.22 \cdot 10^{-6}$ & - & $5.86 \cdot 10^{-6}$ \\
\hline & Electrolyte volume fraction $\left(\varepsilon_{k}\right)$ & $\%$ & 33.5 & 47 & 25 \\
\hline & Active material volume fraction $\left(\varepsilon_{\text {act }, k}\right)$ & $\%$ & 66.5 & - & 75 \\
\hline & Bruggeman exponent $(b)$ & - & 1.5 & 1.5 & 1.5 \\
\hline & Solid-phase lithium diffusivity $\left(D_{\mathrm{s}, k}\right)$ & $\mathrm{m}^{2} \mathrm{~s}^{-1}$ & Eq. [10] & - & Eq. [10] \\
\hline & Exchange current density $\left(j_{0}\right)$ & $\mathrm{A} \mathrm{cm}^{-2}$ & Eq. [14] & - & Eq. [14] \\
\hline & Maximum concentration $\left(c_{\mathrm{s}, k}^{\max }\right)$ & $\mathrm{mol} \mathrm{m}^{-3}$ & $51765^{23}$ & - & $29583^{23}$ \\
\hline & Density $\left(\rho_{S}\right)^{*}$ & $\mathrm{~kg} \mathrm{~m}^{-3}$ & 625 & 1620 & 1740 \\
\hline & Current collector density & $\mathrm{kg} \mathrm{m}^{-3}$ & 2702 & - & 8933 \\
\hline & Specific heat capacity $\left(C_{p}\right)^{*}$ & $\mathrm{~J} \mathrm{~kg}^{-1} \mathrm{~K}^{-1}$ & Eq. [1] & Eq. [1] & Eq. [1] \\
\hline & Current collector specific heat capacity & $\mathrm{J} \mathrm{kg}^{-1} \mathrm{~K}^{-1}$ & Eq. [S4] & - & Eq. [S5] \\
\hline & Thermal conductivity $(\lambda)^{*}$ & $\mathrm{~W} \mathrm{~m}^{-1} \mathrm{~K}^{-1}$ & Table 6 & $0.334^{43}$ & Table 6 \\
\hline & Current collector thermal conductivity & $\mathrm{W} \mathrm{m}^{-1} \mathrm{~K}^{-1}$ & 237 & - & Eq. [S6] \\
\hline & Open Circuit Voltages $\left(U_{k}\right)$ & $\mathrm{V}$ & Eq. $[S 7]^{23}$ & - & Eq. $[S 8]^{23}$ \\
\hline & Entropic term $\left(\frac{d U}{d T}\right)$ & $\mathrm{V} \mathrm{K}^{-1}$ & Eq. [16] & - & Eq. [17] \\
\hline & Solid-phase electronic conductivity $\left(\sigma_{\mathrm{s}, k}\right)$ & $\mathrm{S} \mathrm{m}^{-1}$ & 0.847 & - & $215^{23}$ \\
\hline & Electronic conductivity activation energy & $\mathrm{kJ} \mathrm{mol}^{-1}$ & 3.5 & - & - \\
\hline \multirow{5}{*}{$\overline{0}$} & Effective heat transfer area of jellyroll & $\mathrm{m}^{2}$ & \multicolumn{3}{|c|}{$4.84 \cdot 10^{-3}$} \\
\hline & Effective heat transfer area of cell & $\mathrm{m}^{2}$ & \multicolumn{3}{|c|}{$5.31 \cdot 10^{-3}$} \\
\hline & Jellyroll volume & $\mathrm{m}^{3}$ & \multicolumn{3}{|c|}{$2.13 \cdot 10^{-5}$} \\
\hline & Cell volume & $\mathrm{m}^{3}$ & \multicolumn{3}{|c|}{$2.42 \cdot 10^{-5}$} \\
\hline & Jellyroll effective heat capacity & $\mathrm{J} \mathrm{kg}^{-1} \mathrm{~K}^{-1}$ & \multicolumn{3}{|c|}{866} \\
\hline \multirow{7}{*}{ 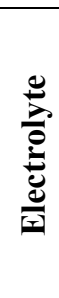 } & Ionic diffusivity $\left(D_{\mathrm{e}}\right)$ & $\mathrm{m}^{2} \mathrm{~s}^{-1}$ & \multicolumn{3}{|c|}{ Eq. $[19]^{79}$} \\
\hline & Ionic conductivity $(\kappa)$ & $\mathrm{S} \mathrm{m}^{-1}$ & \multicolumn{3}{|c|}{ Eq. $[18]^{79}$} \\
\hline & Transference number $\left(t^{+}\right)$ & - & \multicolumn{3}{|c|}{ Eq. $[20]^{79}$} \\
\hline & Thermodynamic factor (TDF) & - & \multicolumn{3}{|c|}{ Eq. $[21]^{79}$} \\
\hline & Density $\left(\rho_{l}\right)$ & $\mathrm{kg} \mathrm{m}^{-3}$ & \multicolumn{3}{|c|}{$1280^{35}$} \\
\hline & Specific heat capacity & $\mathrm{J} \mathrm{kg}^{-1} \mathrm{~K}^{-1}$ & \multirow{2}{*}{\multicolumn{3}{|c|}{$229^{35}$}} \\
\hline & Thermal conductivity & $\mathrm{W} \mathrm{m}{ }^{-1} \mathrm{~K}^{-1}$ & & & \\
\hline
\end{tabular}




\subsubsection{Validation}

The parameters outlined in Table 8 have been made available in PyBaMM and can used as inputs for different physics-based models to predict battery behaviour in various conditions. To validate the determined parameters, we compared experimental data to simulations using the DFN model coupled to a thermal model. These equations are outlined in Tables S1 and $\mathrm{S} 2$. The model was used to predict the voltage and temperature profiles at C-rates of $0.5 \mathrm{C}$, $1 \mathrm{C}$, and $2 \mathrm{C}$, at $0{ }^{\circ} \mathrm{C}, 10^{\circ} \mathrm{C}$ and $25^{\circ} \mathrm{C}$. These 9 datasets are available in a data repository, however for this paper we study five cases: (i) $0.5 \mathrm{C} \mid 25^{\circ} \mathrm{C}$, (ii) $0.5 \mathrm{C} \mid 0^{\circ} \mathrm{C}$, (iii) $0.5 \mathrm{C} \mid 10{ }^{\circ} \mathrm{C}$, (iv) $1 \mathrm{C} \mid 25^{\circ} \mathrm{C}$, and $(\mathrm{v}) 2 \mathrm{C} \mid 25^{\circ} \mathrm{C} .{ }^{25}$

The initial concentrations for the positive and negative electrodes were set to $13975 \mathrm{~mol} \mathrm{~m}^{-3}$ and $28866 \mathrm{~mol} \mathrm{~m}^{-3}$, respectively, which correspond to stoichiometries of 0.27 and 0.98 . Note that the initial concentrations can vary significantly from cell to cell, so their values were determined by manually adjusting the rest voltage at the beginning of the simulation to the experimental data. To achieve good agreement between the simulated and experimental data adjusting of a few other parameters values is needed. This was initially carried out based on the voltage profile of the $1 \mathrm{C} \mid 25^{\circ} \mathrm{C}$ case, for this only one parameter needed manual tuning: the positive electrode diffusivity. This tuning was done manually by trial and error by setting a multiplicative factor to the diffusivity function (illustrated in Fig S8) until a good qualitative agreement was observed with the experimental data. We found that a factor of 2.7, the same as used in a previous work, ${ }^{23}$ gave good agreement with experimental data, and even though this can seem a significant adjustment, note that it is within the typical variability between different cells (see Fig S8). The negative electrode diffusivity, on the other hand, was adjusted but instead of manual tuning we used the factor of 3.03 found earlier, which gives a good agreement with experimental data. This contrasts to the previous electrochemical parameterisation for this cell, requiring the negative electrode diffusion coefficient to be increased $1800 \%$ from the experimentally determined value, which demonstrates the improvement in simulated data when parameter value variability is considered and not taken to be a constant. ${ }^{23}$ The temperature profiles for the $1 \mathrm{C}$ and $2 \mathrm{C}$ cases demonstrated good agreement, although as the $0.5 \mathrm{C}$ is dominated by reversible heat it is more sensitive to entropic term. Therefore, in the $0.5 \mathrm{C} / 25^{\circ} \mathrm{C}$ case the negative electrode entropic term had to be tuned. This adjustment involved excluding the lower entropic term values, see Figure 13. In summary, the values of three parameters had to be adjusted to achieve good agreement for the temperature and voltage profiles.

The quality of tuning was confirmed by comparing agreement of the different C-rates at $25^{\circ} \mathrm{C}$, see Figure 15. Since the parameters were tuned based on the $1 \mathrm{C}$ case there is excellent agreement here, the voltage profiles for $0.5 \mathrm{C}$ and $2 \mathrm{C}$ have disagreement for the final voltage during relaxation. However, this could be improved by adjusting the electrode diffusivities explicitly for these cases-tuning is likely needed depending on the operational conditions being used in the simulation. Next, we compare the data for the $1 \mathrm{C}$ case at various temperatures, see Figure 16. This allows us to observe whether the temperature dependencies of the electrochemical parameters have been mapped adequately. The comparison at $10{ }^{\circ} \mathrm{C}$ and $25^{\circ} \mathrm{C}$ illustrates good agreement for both the voltage and temperature profiles. However, the agreement between experimental and simulated data is 
worse at $0{ }^{\circ} \mathrm{C}$, this is due to this temperature being outside the range for measured parameter values - there is likely an interplay of different effects meaning that the Arrhenius relationship cannot be applied for the entire operating temperature range. The heat transfer coefficient was adjusted manually to a value of $15 \mathrm{~W} \mathrm{~m}^{-2} \mathrm{~K}^{-1}$, which is within the expected range of values.

To verify the improvement in simulations accounting for the parameter-dependencies and thermal behaviour for the $\mathrm{M} 50$, the simulations were compared to a C-rate discharge that the parameters were not tuned to. The diffusivity needs tuning due to underestimation in the solid-state coefficient during GITT, and in this case we have tuned to $1 \mathrm{C}$ for both the Chen et al. parameter set and those outlined in this paper, they both provide good agreement for this C-rate, see Figure 17. However, if these simulations are used to observe cell behave

under various C-rates then it is not possible to tune to each C-rate, to observe how these parameters compare to the experimental data for those C-rates not specifically tuned for we repeat the simulations at $C / 2$ and compare to the experimental data. For this case the new parameter set reduces the RMSE (root mean square error) by $27 \%$ (RMSE is 0.14 for Chen 2020 parameter set and 0.10 for ORegan 2021 parameter set). This demonstrates that including these parameter dependencies improves the prediction under conditions that could not be specifically tuned to. This relaxation can also be captured better in the simulation by capturing particle size distributions in the simulations. ${ }^{80}$ Reducing the number of parameters needed to be tuned and reducing the magnitude of tuning needed by including non-constant values. There is always deviation between the experimentally measured parameters and the values needed to provide agreement with simulations, so tuning is a necessary step. This is due to errors introduced by the unknown cell composition, damage to materials during teardown, errors introduced in the analysis and the simplicity and assumptions of the models in capturing the full kinetic and thermodynamic data.

It should be noted that the computational time required in PyBaMM can be reduced by removing parameter granularity, improving the solver methods, or using a model type with lower complexity. For example, the thermal single particle model with electrolyte (TSPMe) demonstrates similar quality results and is an order of magnitude faster. ${ }^{25}$ 

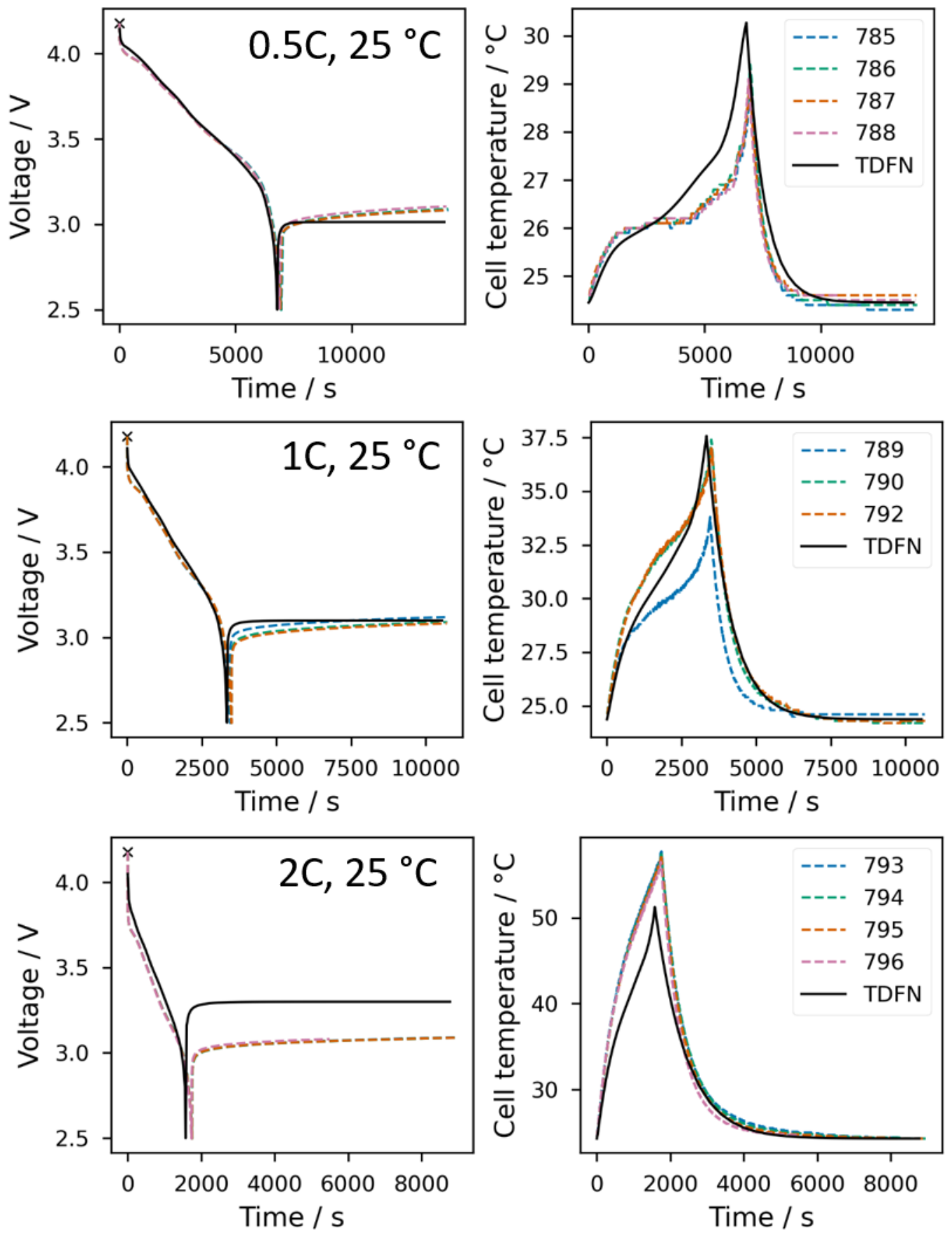

Figure 15. Experimental and simulated voltage (left) and temperature (discharge) profiles for a $0.5 \mathrm{C}, 1 \mathrm{C}$, and $2 \mathrm{C}$ discharge at $25^{\circ} \mathrm{C}$. The experimental data was from tests on four cylindrical cells (the cell ID numbers are listed in the legend), while the simulated data was using the fully parameterised DFN model. 

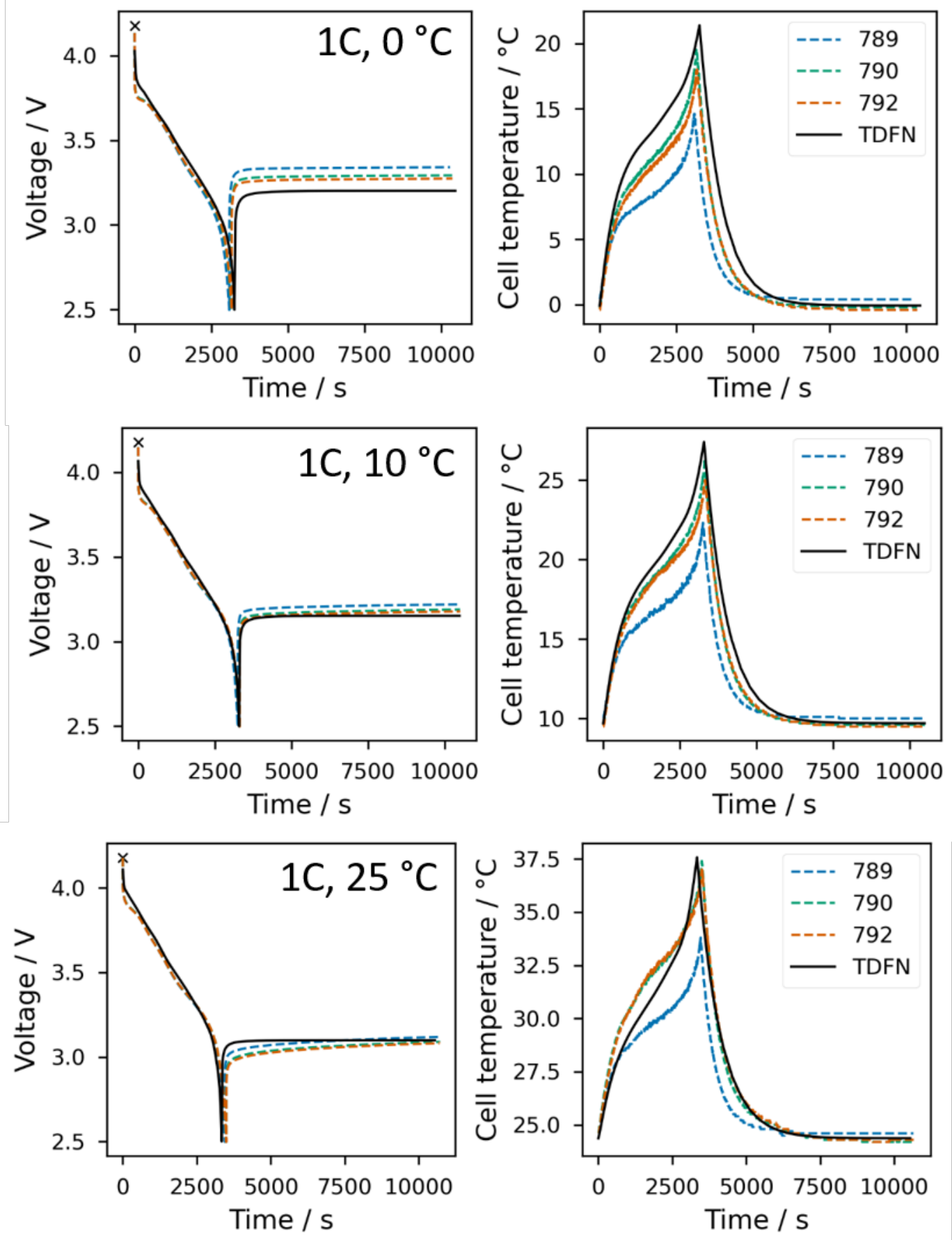

Figure 16. Experimental and simulated voltage (left) and temperature (discharge) profiles for a $1 \mathrm{C}$ discharge at $0{ }^{\circ} \mathrm{C}, 10^{\circ} \mathrm{C}, 25^{\circ} \mathrm{C}$. The experimental data was from tests on three cylindrical cells (the cell ID numbers are listed in the legend), while the simulated data was using the fully parameterised DFN model. 

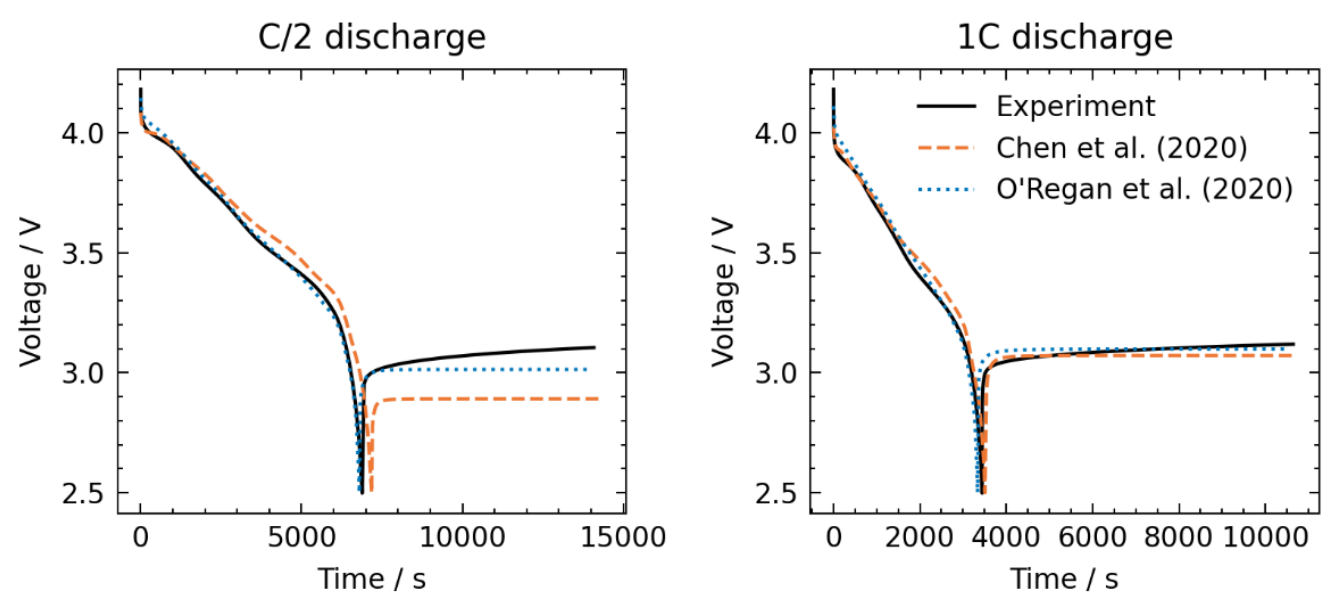

Figure 17. Simulations for the previous parameter set of the LG M50 (Chen 2020, orange dashed line) and the parameter set that takes into account parameter-dependencies and thermal behaviour (This work 2021, blue dotted line) compared to the experimental data. The parameters in both cases have been tuned to the data for the $1 \mathrm{C}$ discharge and then these same parameters are used for the $\mathrm{C} / 2$ simulation to demonstrate that the discharge behaviour and relaxation is captured better for $\mathrm{C}$-rates that deviate from the tuned values. C/2 RMSE (root mean square error) for 0.10 for Chen2020 and 0.14 for this work.

Future work to improve the accuracy of the parameterisation includes mapping the lithium concentration of the thermal parameters (e.g. specific heat capacity and thermal conductivity), rather than at a single stoichiometry. This relationship was not considered here due to the stability of active materials in ambient conditions. In situ methods that allow measurement as a function of lithium concentration would allow the changes in these parameters that occur during battery operation to be captured. Additionally, the requirement to increase the solid-phase diffusivity value of each electrode highlights limitations in the analytical approach and DFN theory. It is assumed that particles are spherical and monodisperse despite the electrode microstructure being heterogeneous. Ignoring these effects in parameter evaluation and the model is one of the main reasons for disagreement with experimental data. Accounting for electrode inhomogeneity will improve model accuracy, for example including size distribution and non-spherical morphologies.

\subsection{Conclusions}

This paper outlines the parameterisation methodology for a 3D thermal-electrochemical model for a high-energy lithium-ion battery. The electrochemical and thermal relationships in a high energy density cylindrical cell (21700) and the electrodes have been mapped through electrochemical testing at different temperatures, to provide diffusivity, exchange current and electronic conductivity profiles. Additional thermal properties, specific heat capacity, thermal conductivity and the entropic terms are measured using thermal characterisation techniques.

The thermal parameters of the cell provide information for a 3D thermal model, whilst the electrode parameters provide information for OD, 1D and 2D models. A OD electrochemical- 
thermal model has been derived with the obtained parameters, providing improved fit to the validation data performed on the cell. Further improvements are likely through expansion of this model to 3D, but further modelling work is required.

The physical parameters of the negative and positive electrode are very similar, the positive electrode had slightly lower thickness, at $76 \mu \mathrm{m}$ rather than $84 \mu \mathrm{m}$, a higher pore volume of $33,5 \%$ compared to $25 \%$ and a slightly lower mean particle radius of $5.2 \mu \mathrm{m}$ rather than 5.9 $\mu \mathrm{m}$. Whereas the thermal properties are also very similar with the Specific hear capacity (Cp) at 990 and $950 \mathrm{~J} \mathrm{~kg}^{-1} \mathrm{~K}^{-1}$ respectively, thermal diffusivity, $(\alpha)$ is 0.282 compared to $2.266 \mathrm{~mm}^{2}$ $\mathrm{s}^{-1}$ and the thermal conductivity 0.892 compared to 4.058 for the dry electrodes at room temperature, which corresponds to the difference in electronic conductivity of 0.847 and 215 $\mathrm{Sm}^{-1}$. Indicating that the thermal and electronic conductivities can be linked.

The negative electrode likely limits the maximum power observed by the cell, as observed from the lower diffusion coefficient and current exchange density compared to the positive electrode over the full SOC window. At stoichiometries of $\mathrm{Li}_{x} \mathrm{C}_{6}$, where $\mathrm{x}=0.45$ and 0.85 activation energies of up to $60 \mathrm{kJK}^{-1}$ and low diffusion coefficients of $5 \times 10^{-13} \mathrm{~cm}^{-2} \mathrm{~s}^{-1}$ at $25^{\circ} \mathrm{C}$ were observed. Some of these limitations may be compensated for at $45^{\circ} \mathrm{C}$ as the exchange current in the negative electrode surpasses that of the positive electrode and the diffusion coefficient increases in the negative by an order of magnitude to $2 \times 10^{-12} \mathrm{~cm}^{-2} \mathrm{~s}^{-1}$. Whereas for the positive electrode the lowest diffusion coefficients were observed for $\mathrm{Li}_{x} \mathrm{MO}_{2}$, at $\mathrm{x}=0.32$ and 0.81 , which are just within the full cell cycling window $(0.26 \leq x \leq 91), 7 \times 10^{-12} \mathrm{~cm}^{-2} \mathrm{~s}^{-1}$ was obtained at room temperature which increased to $2 \times 10^{-11}$ at $45^{\circ} \mathrm{C}$, above stoichiometry of $\mathrm{x}=0.8$ the activation energy also doubled to $24 \mathrm{kJK}^{-1}$. The changes in temperature change the ionic transport by orders of magnitude and the reaction rates increase.

In terms of application to the modelling, the incorporation of state of charge or stoichiometry and temperature variable conductivities and diffusivities have improved the model fit before tuning. The electrochemical parameters tuning was reduced from four parameters; diffusivities and maximum concentrations, to only the solid-phase diffusivities. The magnitude of tuning was also reduced, the tuning needed of the negative electrode diffusivity was decreased by $303 \%$. The diffusivity of the negative electrode is key to improving the models for high energy cells, large changes in magnitude of the diffusivity with temperature variation with only small changes in SOC, cause difficulties in fitting. To improve the fits at higher rates, the effect of the ohmic resistance and heating must be taken into consideration. As observed by the fit of the 2D discharge and relaxation, the actual observed voltage is significantly lower than the estimated. This is likely because the diffusion coefficient is being underestimated and Ohmic heating is causing faster movement of the lithium ions in the solid, resulting in more lithium transport over that time frame.

In summary, a parameterisation methodology is outlined, which uses electrochemical and thermal techniques, illustrating the parameter variability caused by local and global changes in temperature or lithium concentration. This methodology is chemistry and format-agnostic and can be applied to different cell types to increase the availability of 3D thermal-electrochemical parameters. Insight into the diffusion and reaction rate kinetics show the limiting electrodes. Further work with these parameters would be to design, predict 
and validate faster charging and discharging protocols, through understanding the changes in rate kinetics at different states of charge and with temperature.

\section{Data Availability}

The parameter set in Table 8 has been made available in the PyBaMM software package. This open-source software is a development platform for physics-based modelling tools. ${ }^{32}$ Further information can be found at https://www.pybamm.org/.

The data repository with parameter values for the electrode solid-phase diffusivity, entropic term, exchange current density, electronic conductivity, specific heat capacity, and thermal conductivity can be found at Zenodo (https://zenodo.org/) under the DOI 10.5281/zenodo.5171874. The data repository containing the validation data for cells tested under different operating conditions can be found at Zenondo under the DOI 10.5281/zenodo.4864437.

\section{Acknowledgements}

The authors would like to acknowledge the help of Dr. Kate Robbins and Dr. Mike Jenkins with DSC data collection and Fabia Beckenstein with thermal diffusivity data collection and the financial support from The Faraday Institution, MSM project faraday.ac.uk; EP/S003053/1), grant number FITG011 and FIRG003

\section{References}

1 J. B. Goodenough and Y. Kim, Chem. Mater., 2010, 22, 587-603.

2 G. E. Blomgren, J. Electrochem. Soc., 2017, 164, A5019-A5025.

3 A. Kwade, W. Haselrieder, R. Leithoff, A. Modlinger, F. Dietrich and K. Droeder, Nat. Energy, 2018, 3, 290-300.

4 W. Mei, H. Chen, J. Sun and Q. Wang, Sustain. Energy Fuels, 2019, 3, 148-165.

5 S. Arora and A. Kapoor, Batteries, , DOI:10.3390/batteries5040070.

6 A. Hales, L. B. Diaz, M. W. Marzook, Y. Zhao, Y. Patel and G. Offer, J. Electrochem. Soc., 2019, 166, A2383-A2395.

7 T. G. Tranter, R. Timms, P. R. Shearing and D. J. L. Brett, J. Electrochem. Soc., 2020, 167, 160544.

8 W. He, M. Pecht, D. Flynn and F. Dinmohammadi, Energies, 2018, 11, 1-24.

9 J. Newman and W. Tiedemann, AIChE J., 1975, 21, 25-41.

10 J. Newman and W. Tiedemann, J. Electrochem. Soc., 1993, 140, 1961.

11 B. Wu, V. Yufit, M. Marinescu, G. J. Offer, R. F. Martinez-Botas and N. P. Brandon, J. Power Sources, 2013, 243, 544-554. 
14 X. Zuo, J. Zhu, P. Müller-Buschbaum and Y. J. Cheng, Nano Energy, 2017, 31, 113-143.

15 C. Chen, A. Verma and P. P. Mukherjee, J. Electrochem. Soc., 2017, 164, E3146-E3158.

16 M. Ecker, P. Dechent, T. K. D. Tran, A. Warnecke, S. Käbitz and D. U. Sauer, J. Electrochem. Soc., 2015, 162, A1836-A1848.

17 J. Schmalstieg, C. Rahe, M. Ecker and D. U. Sauer, J. Electrochem. Soc., 2018, 165, A3799-A3810.

18 G. Liebig, G. Gupta, U. Kirstein, F. Schuldt and C. Agert, Batteries, 2019, 5, 62.

19 G. Liebig, U. Kirstein, S. Geißendörfer, F. Schuldt and C. Agert, Batteries, 2020, 6, 3.

20 M. J. Lain, J. Brandon and E. Kendrick, Batteries, 2019, 5, 64.

21 M. J. Lain and E. Kendrick, J. Power Sources, 2021, 493, 229690.

22 J. Sturm, A. Rheinfeld, I. Zilberman, F. B. Spingler, S. Kosch, F. Frie and A. Jossen, J. Power Sources, 2019, 412, 204-223.

23 C.-H. Chen, F. Brosa Planella, K. O’Regan, D. Gastol, W. D. Widanage and E. Kendrick, J. Electrochem. Soc., 2020, 167, 080534.

24 A. Zülke, I. Korotkin, J. M. Foster, M. Nagarathinam, H. Hoster and G. Richardson, J. Electrochem. Soc., 2021, 168, 120522.

25 F. Brosa Planella, M. Sheikh and W. D. Widanage, Electrochim. Acta, 2021, 388, 138524.

26 C. Bhat and J. Channegowda, Energy Storage, 2021, 1-9.

27 T. G. Tranter, R. Timms, T. M. M. Heenan, S. G. Marquis, V. Sulzer, A. Jnawali, M. D. R. Kok, C. P. Please, S. J. Chapman, P. R. Shearing and D. J. L. Brett, J. Electrochem. Soc., 2020, 167, 110538.

28 G.-H. Kim, K. Smith, K.-J. Lee, S. Santhanagopalan and A. Pesaran, J. Electrochem. Soc., 2011, 158, A955.

29 H. Lundgren, P. Svens, H. Ekström, C. Tengstedt, J. Lindström, M. Behm and G. Lindbergh, J. Electrochem. Soc., 2016, 163, A309-A317.

30 M. Doyle, T. Fuller and J. Newman, J. Electrochem. Soc., 1993, 140, 1526.

31 N. A. Zacharias, D. R. Nevers, C. Skelton, K. Knackstedt, D. E. Stephenson and D. R. Wheeler, J. Electrochem. Soc., 2013, 160, A306-A311.

32 V. Sulzer, S. G. Marquis, R. Timms, M. Robinson and S. J. Chapman, J. Open Res. Softw., 2021, 9, 14.

33 J. A. E. Andersson, J. Gillis, G. Horn, J. B. Rawlings and M. Diehl, Math. Program. Comput., 2019, 11, 1-36.

34 T. R. B. G.F. Hewitt, G.L. Shires, Process Heat Transfer, CRC Press, London, 1993.

35 P. Bohn, G. Liebig, L. Komsiyska and G. Wittstock, J. Power Sources, 2016, 313, 30-36. 
H. Maleki, J. Electrochem. Soc., 1999, 146, 947.

37 R. Kantharaj and A. M. Marconnet, Nanoscale Microscale Thermophys. Eng., 2019, 23, 128-156.

P. Gotcu, W. Pfleging, P. Smyrek and H. J. Seifert, Phys. Chem. Chem. Phys., 2017, 19, 11920-11930.

39 G. R. Stewart, Rev. Sci. Instrum., 1983, 54, 1-11.

40 S. Bak, E. Hu, Y. Zhou, X. Yu, S. D. Senanayake, S. Cho, K. Kim, K. Y. Chung, X. Yang and K. Nam, ACS Appl. Mater. Interfaces, 2014, 6, 22594-22601.

41 S. S. Madani, E. Schaltz and S. K. Kær, Batteries, 2018, 4, 1-16.

42 L. Wei, Z. Lu, F. Cao, L. Zhang, X. Yang, X. Yu and L. Jin, Int. J. Energy Res., 2020, 44, 9466-9478.

43 S. C. Chen, C. C. Wan and Y. Y. Wang, J. Power Sources, 2005, 140, 111-124.

44 H.-K. Kim, J. H. Choi and K.-J. Lee, J. Electrochem. Soc., 2019, 166, A1769-A1778.

45 K. Takano, Y. Saito, K. Kanari, K. Nozaki, K. Kato, A. Negishi and T. Kato, J. Appl. Electrochem., 2002, 32, 251-258.

46 N. Co, M. O. Ncm, S. Full, F. Reuter, J. E. Soc, F. Reuter, A. Baasner, J. Pampel, M. Piwko, H. Althues, S. Kaskel and S. Dörfler, , DOI:10.1149/2.0431914jes.

47 K. Märker, P. J. Reeves, C. Xu, K. J. Griffith and C. P. Grey, Chem. Mater., 2019, 31, 25452554.

48 W. Weppner and R. A. Huggins, J. Electrochem. Soc., 1977, 124, 1569-1578.

49 L. Stolz, G. Homann, M. Winter and J. Kasnatscheew, Mater. Today, 2021, 44, 9-14.

50 D. Sauerteig, N. Hanselmann, A. Arzberger, H. Reinshagen, S. Ivanov and A. Bund, J. Power Sources, 2018, 378, 235-247.

51 K. Pan, F. Zou, M. Canova, Y. Zhu and J. H. Kim, J. Power Sources, 2019, 413, 20-28.

52 M. A. Cabañero, N. Boaretto, M. Röder, J. Müller, J. Kallo and A. Latz, J. Electrochem. Soc., 2018, 165, A847-A855.

53 R. Jung, M. Metzger, F. Maglia, C. Stinner and H. A. Gasteiger, J. Electrochem. Soc., 2017, 164, A1361-A1377.

54 M. Winter, J. O. Besenhard, M. E. Spahr and P. Novák, Adv. Mater., 1998, 10, 725-763.

55 W. Lee, S. Muhammad, T. Kim, H. Kim, E. Lee, M. Jeong, S. Son, J. H. Ryou and W. S. Yoon, Adv. Energy Mater., 2018, 8, 1-12.

56 R. Amin and Y.-M. Chiang, J. Electrochem. Soc., 2016, 163, A1512-A1517.

57 M. D. Levi and D. Aurbach, J. Phys. Chem. B, 1997, 101, 4641-4647.

58 A. Latz, T. Danner, B. Horstmann and T. Jahnke, Chemie-Ingenieur-Technik, 2019, 91, 758-768. 
60 N. Takami, J. Electrochem. Soc., 1995, 142, 371.

61 T. L. Kulova, A. M. Skundin, E. A. Nizhnikovskii and A. V. Fesenko, Russ. J. Electrochem., 2006, 42, 259-262.

62 I. Umegaki, S. Kawauchi, H. Sawada, H. Nozaki, Y. Higuchi, K. Miwa, Y. Kondo, M. Månsson, M. Telling, F. C. Coomer, S. P. Cottrell, T. Sasaki, T. Kobayashi and J. Sugiyama, Phys. Chem. Chem. Phys., 2017, 19, 19058-19066.

63 N. Jin, D. L. Danilov, P. M. J. Van den Hof and M. C. F. Donkers, Int. J. Energy Res., 2018, 42, 2417-2430.

64 T. R. Jow, M. B. Marx and J. L. Allen, J. Electrochem. Soc., 2012, 159, A604-A612.

65 M. C. Smart and B. V. Ratnakumar, J. Electrochem. Soc., 2011, 158, A379.

66 A. S. Keefe, S. Buteau, I. G. Hill and J. R. Dahn, J. Electrochem. Soc., 2019, 166, A3272A3279.

67 E. Antolini, Solid State lonics, 2004, 170, 159-171.

68 S. Chacko and Y. M. Chung, J. Power Sources, 2012, 213, 296-303.

69 X. Zhang, Electrochim. Acta, 2011, 56, 1246-1255.

70 J. Hong, H. Maleki, S. Al Hallaj, L. Redey and J. R. Selman, J. Electrochem. Soc., 1998, 145, 1489-1501.

71 V. V. Viswanathan, D. Choi, D. Wang, W. Xu, S. Towne, R. E. Williford, J. G. Zhang, J. Liu and Z. Yang, J. Power Sources, 2010, 195, 3720-3729.

72 S. Wang, Chinese Phys. B, 2016, 25, 010509.

73 S. Basu, R. S. Patil, S. Ramachandran, K. S. Hariharan, S. M. Kolake, T. Song, D. Oh, T. Yeo and S. Doo, J. Power Sources, 2015, 283, 132-150.

74 M. Maures, Y. Zhang, C. Martin, J. Delétage, J. Vinassa and O. Briat, Microelectron. Reliab., 2019, 100-101, 113364.

75 Y. Reynier, R. Yazami and B. Fultz, J. Power Sources, 2003, 119-121, 850-855.

76 J. Sturm, A. Rheinfeld, I. Zilberman, F. B. Spingler, S. Kosch, F. Frie and A. Jossen, J. Power Sources, 2019, 412, 204-223.

77 L. Gu, J. Y. Gui, J. V. Wang, G. Zhu and J. Kang, Energy, 2019, 178, 21-32.

78 J. Landesfeind, A. Ehrl, M. Graf, W. A. Wall and H. A. Gasteiger, J. Electrochem. Soc., 2016, 163, A1254-A1264.

79 J. Landesfeind and H. A. Gasteiger, J. Electrochem. Soc., 2019, 166, A3079-A3097.

80 T. Kirk, J. Evans, C. Please and J. Chapman, ArXiv:2006.12208. 